\title{
Effectiveness of Ergonomic Job Stress Intervention (ERGO-JSI) on the Work Ability Index and Job Stress of Workers in an Auto Parts Manufacturers
}

\author{
Anooshirvan Safari ${ }^{1}$ (D), Shahnaz Tabatabaei²*iD), Mahnaz Saremi ${ }^{3}$ it \\ 1. MSc. Student, Department of Ergonomics, School of Public Health and Safety, Shahid Beheshti University of Medical \\ Sciences, Tehran, Iran \\ 2. Associate Professor, Department of Ergonomics, School of Public Health and Safety, Shahid Beheshti University of \\ Medical Sciences, Tehran, Iran \\ 3. Associate Professor, Department of Ergonomics, School of Public Health and Safety, Shahid Beheshti University of \\ Medical Sciences, Tehran, Iran
}

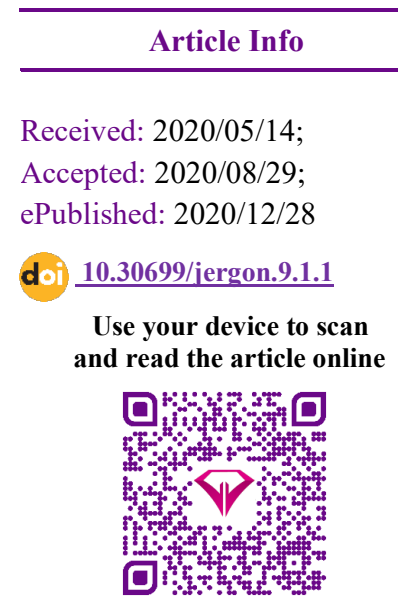

Corresponding Author Shahnaz Tabatabaei Associate Professor, Department of Ergonomics, School of Public Health and Safety, Shahid Beheshti University of Medical Sciences, Tehran, Iran Email: sh.tabatabaei@sbmu.ac.ir

\section{ABSTRACT}

Background and Objectives: In the automotive industry, assemblers are at the risk of job stress. There is relationship between job stress and work ability index, and job stress can impact on work ability index negatively. Therefore, this study investigates the effect of ergonomic job stress intervention (Ergo-JSI) on the work ability index and job stress of assemblers in an auto parts factory.

Methods: It was an interventional study with pre- and post-test design in the assembly section of an auto parts factory. The sample group included 80 persons who were working in this section and they were selected totally. The interventional Ergonomics-based on Job Stress Program was performed for eight weeks. Job stress questionnaires (BJSQ), work ability index (WAI), ergonomic check points (ECP), and stress prevention in the workplace (International Labor Organization) were used as research tools.

Results: The ergonomic job stress intervention (Ergo-JSI) was found to be significant on the work ability index $(P<0.001)$. The level of work ability index was increased by $16.25 \%$ for workers $(P=0.01)$. Furthermore, the job stress was decreased significantly $(P<0.05)$. The quantitative changes in the level of job stress towards reduction were based on the BJSQ criteria A $(51.25 \%)$ and criteria $\mathrm{B}(27.5 \%)$; these differences were found to be significant $(P<0.001)$.

Conclusion: Individual and organizational approaches which used for the interventional Ergonomic based on Job Stress Management Program has been effective on the decreasing of job stress and the increasing of work ability index of assemblers. Therefore, this Participatory Ergonomics Program which has an integrated approach can be improved the mental health of staff.

Keywords: Job stress management, Work ability index, Ergonomic intervention, Automotive industry

Copyright (C) 2021, This is an original open-access article distributed under the terms of the Creative Commons Attribution-noncommercial 4.0 International License which permits copy and redistribute of the material just in noncommercial usages with proper citation.

\section{How to Cite This Article:}

Safari A, Tabatabaei SH, Mahnaz M. Effectiveness of Ergonomic Job Stress Intervention (ERGO-JSI) on the Work Ability Index and Job Stress of Workers in an Auto Parts Manufacturers t. Iran J Ergon. 2020; 9 (1) :1-14 


\section{Extended Abstract}

\section{Introduction}

In the automotive industry, assemblers are at the risk of job stress. There is relationship between job stress and work ability index, and job stress can impact on work ability index negatively. Therefore, this study investigates the effect of ergonomic job stress intervention (Ergo-JSI) on the work ability index and job stress of assemblers in an auto parts factory [1-3].

\section{Methods}

It was an interventional study with pre- and posttest design in the assembly section of an auto parts factory. The sample group included 80 persons who were working in this section and they were selected totally. The interventional Ergonomicsbased on Job Stress Program was performed for eight weeks. Job stress questionnaires (BJSQ), work ability index (WAI), ergonomic check points (ECP), and stress prevention in the workplace (International Labor Organization) were used as research tools.
This study has been approved by the ethics committee in the research of the Faculty of Health and Neuroscience of Shahid Beheshti University of Medical Sciences in Tehran with the ethics ID IR.SBMU.PHNS.REC.1397.092.

The data obtained in this study were processed with SPSS software version 24 (SPSS Inc., Chicago, Ill., USA). Data analysis was performed by Wilcoxon, paired t-test and sign test at a significance level of 0.05 .

\section{Results}

The ergonomic job stress intervention (Ergo-JSI) was found to be significant on the work ability index $(P<0.001)$. The level of work ability index was increased by $16.25 \%$ for workers $(P=0.01)$. Furthermore, the job stress was decreased significantly $(P<0.05)$. The quantitative changes in the level of job stress towards reduction were based on the BJSQ criteria A $(51.25 \%)$ and criteria B $(27.5 \%)$; these differences were found to be significant $(P<0.001)$.

Table 1. Frequency distribution of personal-occupational characteristics of workers $(n=80)$

\begin{tabular}{|c|c|c|c|c|c|c|}
\hline & & & & $\mathbf{N}$ & & $\%$ \\
\hline & & Mar & & 65 & & 81.25 \\
\hline & & Sin & & 15 & & 18.75 \\
\hline & & Dipl & & 55 & & 68.75 \\
\hline Edı & on & Associate & & 15 & & 18.75 \\
\hline & & Bachelor's deg & & 10 & & 12.50 \\
\hline & $\mathbf{M}$ & SD & Median & & Minimum & Maximum \\
\hline Age & 34.74 & 7.00 & 34.00 & & 24.00 & 55.00 \\
\hline Work history & 8.84 & 6.13 & 8.00 & & 1.00 & 23.00 \\
\hline
\end{tabular}


Table 2. Comparison of scores of ability to do work by areas and total in workers before and after the intervention of Ergo-JSI program

\begin{tabular}{|c|c|c|c|c|c|}
\hline \multirow{2}{*}{$\begin{array}{c}\text { Index of ability to do work by areas and } \\
\text { total }\end{array}$} & \multicolumn{2}{|c|}{ Before the intervention } & \multicolumn{2}{|c|}{ After intervention } & \multirow{2}{*}{ P-value } \\
\hline & M & SD & $\mathbf{M}$ & SD & \\
\hline $\begin{array}{l}\text { Ability to work in connection with the best } \\
\text { time of life }\end{array}$ & 8.55 & 1.19 & 8.93 & 0.92 & $0.001 *<$ \\
\hline $\begin{array}{l}\text { Ability to work in relation to the physical } \\
\text { and mental needs of the job }\end{array}$ & 7.82 & 1.33 & 8.19 & 1.50 & $0.001 *$ \\
\hline Current diseases diagnosed & 4.10 & 2.22 & 4.58 & 2.17 & $0.001 *<$ \\
\hline $\begin{array}{l}\text { Estimating the extent of work-related } \\
\text { injury due to illness and injury }\end{array}$ & 5.49 & 0.95 & 5.58 & 0.90 & $0.083 *$ \\
\hline Sick leave for the past year & 4.75 & 0.52 & 4.75 & 0.52 & $0.999 *$ \\
\hline $\begin{array}{l}\text { Predict the ability to do work in the next } \\
\text { two years }\end{array}$ & 5.58 & 2.02 & 6.10 & 1.61 & $0.001 *$ \\
\hline Intellectual and mental abilities & 2.39 & 0.88 & 2.64 & 0.93 & $0.001 *<$ \\
\hline Total score of work ability index & 36.93 & 3.93 & 38.08 & 3.71 & $0.001 * *<$ \\
\hline
\end{tabular}

** Paired t test

Table 3. Comparison of the level of ability to work in workers before and after the intervention of the Ergo-JSI program

\begin{tabular}{|c|c|c|c|c|}
\hline Score status indicator 0 & work & $\begin{array}{l}\text { Before the } \\
\text { intervention }\end{array}$ & $\begin{array}{c}\text { After the } \\
\text { intervention }\end{array}$ & P-value \\
\hline \multirow{2}{*}{$\begin{array}{l}\text { Weak } \\
(7-27)\end{array}$} & $\mathrm{N}$ & 1 & 2 & \multirow{8}{*}{$0.012 *$} \\
\hline & $\%$ & 1.25 & 2.5 & \\
\hline \multirow{2}{*}{$\begin{array}{c}\text { Medium } \\
(28-36)\end{array}$} & $\mathrm{N}$ & 30 & 19 & \\
\hline & $\%$ & 37.5 & 23.8 & \\
\hline \multirow{2}{*}{$\begin{array}{c}\text { Good } \\
(37-43)\end{array}$} & $\mathrm{N}$ & 47 & 56 & \\
\hline & $\%$ & 58.7 & 70 & \\
\hline \multirow{2}{*}{$\begin{array}{c}\text { Excellent } \\
(44-49)\end{array}$} & $\mathrm{N}$ & 2 & 3 & \\
\hline & $\%$ & 2.5 & 3.8 & \\
\hline
\end{tabular}

Table 4. Comparison of job stress scores by areas and total in workers before and after Ergo-JSI program intervention

\begin{tabular}{|c|c|c|c|c|c|c|}
\hline \multirow{2}{*}{\multicolumn{2}{|c|}{ Job stress by areas and total }} & \multicolumn{2}{|c|}{ Before the intervention } & \multicolumn{2}{|c|}{ After intervention } & \multirow{2}{*}{ P-value } \\
\hline & & M & SD & $\mathbf{M}$ & SD & \\
\hline \multicolumn{2}{|c|}{ Job needs } & 38.71 & 6.37 & 34.05 & 3.47 & $<0.001 *$ \\
\hline \multicolumn{2}{|c|}{ Stress reactions } & 37.09 & 10.09 & 28.94 & 6.00 & $<0.001$ 楼 \\
\hline \multirow{3}{*}{ Job sources } & 8.73 & 2.07 & 7.93 & 1.47 & $<0.001 *$ & \\
\hline & 7.61 & 1.66 & 7.33 & 1.46 & $0.003 *$ & \\
\hline & 4.68 & 1.61 & 4.16 & 1.23 & $0.001 *<$ & \\
\hline \multicolumn{2}{|c|}{ Total score } & 96.81 & 16.66 & 82.40 & 10.20 & $<0.001 * *$ \\
\hline
\end{tabular}

* Wilcoxon Marked Rank Test

** Paired t test 
Table 5. Comparison of workers' job stress before and after Ergo-JSI program intervention based on criteria A and B

\begin{tabular}{|c|c|c|c|c|}
\hline \multicolumn{2}{|c|}{ Job stress levels } & $\mathbf{N}$ & $\%$ & P-value \\
\hline \multirow{3}{*}{$\begin{array}{l}\text { According to criterion A } \\
\text { before the intervention }\end{array}$} & Has a very high stress level & 16 & 20.00 & \multirow{6}{*}{$0.001<*$} \\
\hline & Has moderate to high stress levels & 29 & 36.25 & \\
\hline & Has moderate to low stress levels & 35 & 43.75 & \\
\hline \multirow{3}{*}{$\begin{array}{l}\text { According to criterion A } \\
\text { after the intervention }\end{array}$} & Has a very high stress level & 1 & 1.20 & \\
\hline & Has moderate to high stress levels & 8 & 10.00 & \\
\hline & Has moderate to low stress levels & 71 & 88.8 & \\
\hline \multirow{2}{*}{$\begin{array}{l}\text { According to criterion B } \\
\text { before the intervention }\end{array}$} & Has a very high stress level & 23 & 28.75 & \multirow{4}{*}{$0.001<*$} \\
\hline & Has moderate to low stress levels & 57 & 71.25 & \\
\hline \multirow{2}{*}{$\begin{array}{l}\text { According to criterion B } \\
\text { after the intervention }\end{array}$} & Has a high level of stress & 1 & 1.25 & \\
\hline & Has moderate to low stress levels & 79 & 98.75 & \\
\hline
\end{tabular}

\section{Discussion}

The results of the present study showed that the Ergo-JSI program was effective on the work ability index of assembly workers. There was also a statistically significant relationship between the workers' ability to work index before and after the implementation of the Ergo-JSI intervention program $(P<0.001)$. The mean score of workers' ability to work was at a moderate level before the intervention (36.93 \pm 3.93$)$ and was at a good level after the intervention. In fact, the average score of the assembly workers' work ability index improved from a moderate to a good level $(38.08 \pm 3.71)$. It seems that the increase in work ability index in this study was due to the fact that the Ergo-JSI program had an effect on changing working conditions as well as changes in employees' knowledge, attitudes and behaviors towards job stress problems and how to deal with them. In addition, the ergonomic situation of the workplace due to the reduction of stressful barriers increases work capacity. The communication skills taught at Ergo-JSI also help employees to communicate their feelings and thoughts decisively to co-workers and supervisors, which leads to better mental conditions and increased job motivation [28].

The results of comparing job stress scores related to factory assembly workers based on two criteria A and B (high stress as the highest level of stress response (criterion A) and having a medium or higher level of stress response, with the highest rate of job stress or the least social support in Workplace (criterion B)) before and after the intervention showed that employees' stress levels decreased. Such a reduction is due to the improvement of work environment conditions and individual perception of stressors as a result of the coping mechanism. Therefore, Ergo-JSI improved the work situation by implementing the "Continuous Improvement Program" [30-34].

\section{Conclusion}

Individual and organizational approaches which used for the interventional Ergonomic based on Job Stress Management Program has been effective on the decreasing of job stress and the increasing of work ability index of assemblers. Therefore, this Participatory Ergonomics Program which has an integrated approach can be improved the mental health of staff.

\section{Acknowledgement}

The authors of the article would like to express their sincere gratitude to the esteemed managers and hardworking employees of the Auto Parts Manufacturing Company who assisted and cooperated in conducting this research.

\section{Conflict of Interest}

The authors declared no conflict of interest. 


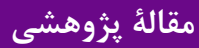

\section{اثربخشى برنامةٔ اركونومى مبتنى بر مديريت استرس شغلى بر شاخص توانايى كار و استرس شغلى كاركران در} يك صنعت توليد قطعات خودرو

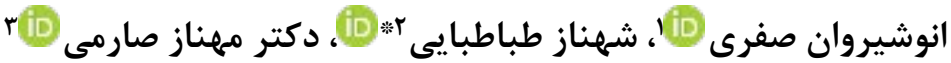

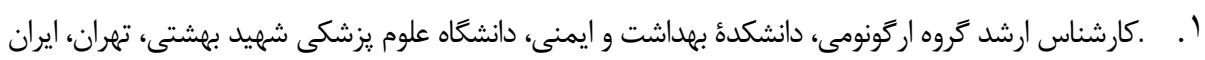

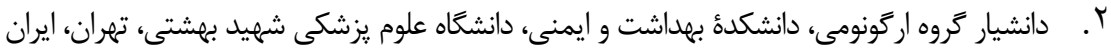

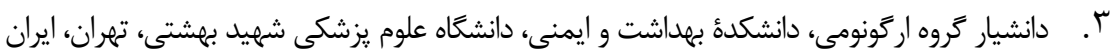

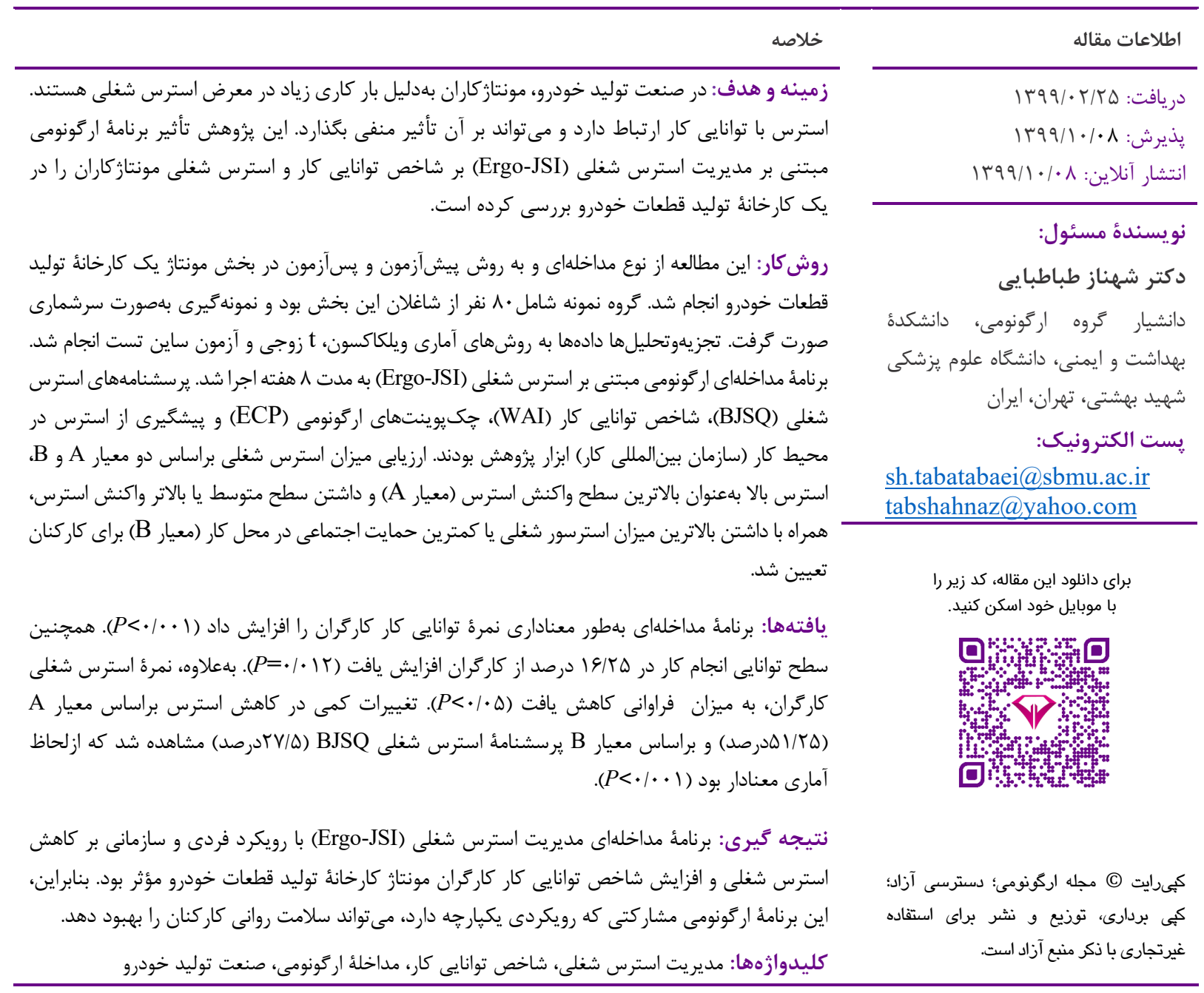

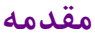

سلامت و ايمنى شغلى ايالاتمتحده آمريكا (NIOSH) استرس شغلى ياسخهاى هيجانى و فيزيكى مضرى است كه درصورت إنمئى

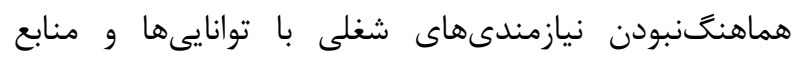

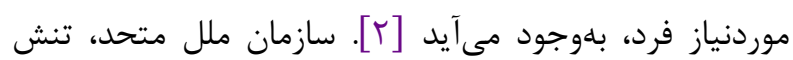

استرس شغلى اغلب بهدليل شرايط نامناسب كارى، مانند حجم كار بالا، نوع شيفت كارى، ساعات طولانى كار و همجنين

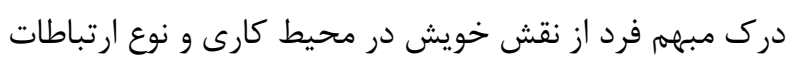

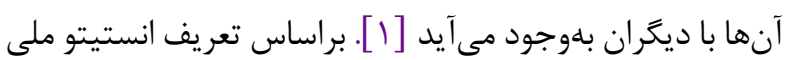


كردهاند [IV] د IV اين مطالعه، فرض شده است، تلفيق رويكردهاى

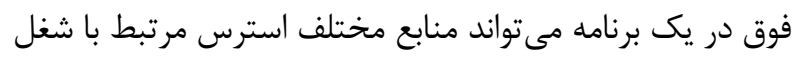

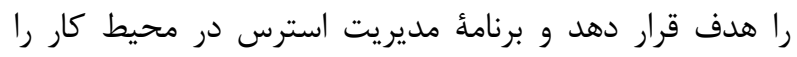

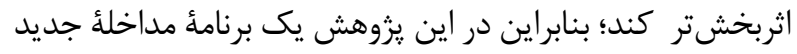

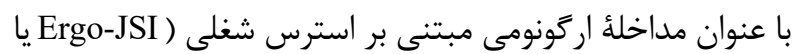
(Intervention Ergonomics-based Job Stress شد كه متشكل از هر دو جزء متمركز بر سازمان، يعنى بهينهسازى

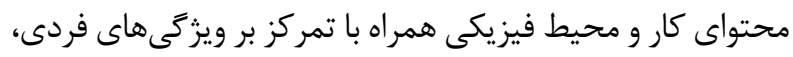
بلهورت آموزش مديريت استرس است. برنامة تر تركيبى از مديريت استرس شغلى همراه با اركونومى يا بهبود شرايط كار بوده و با جهت گيرى واحد، تمركز

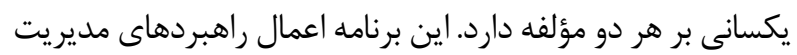

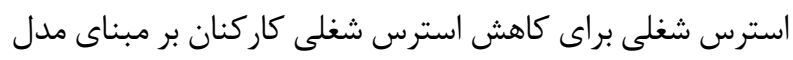
استرس شغلى NIOSH (هارل و مكلينى، Ergo-JSI اجر ا دurnawati - Susy

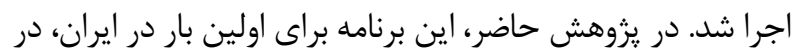

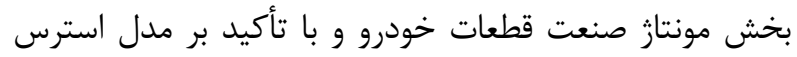

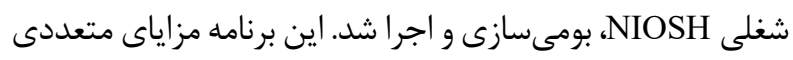

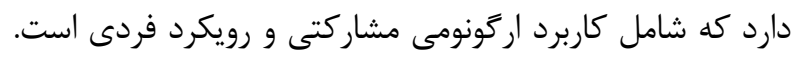

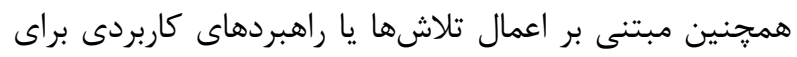
كاهش استرس شغلى از طريق بهبود شرايط كارى و افزايش

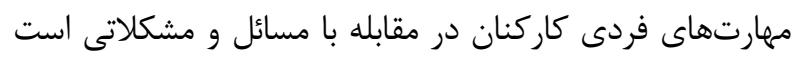

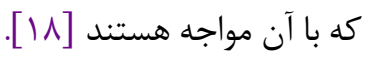
Helali

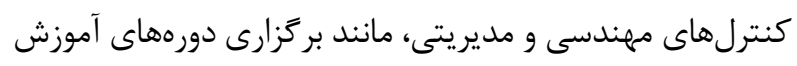

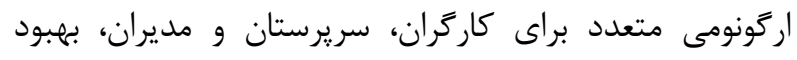

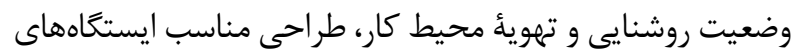

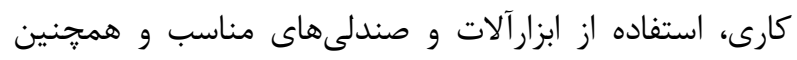
كاهش وزن بار توانستند سبب بهببود وضعيت اركونوميكى كار ارخانئ موردمطالعه شوند [19].

Neag و همكاران در يك برنامة مداخلئ اركونومى همراه با لمان

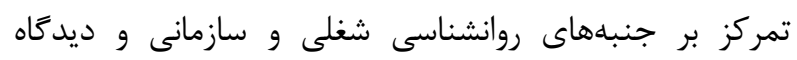

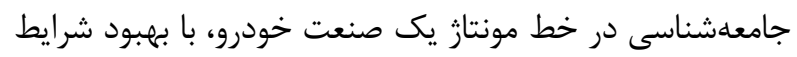
بهداشت شغلى و ايمنى كارگران (كاهش ريسك دارئ فاكتورهاى

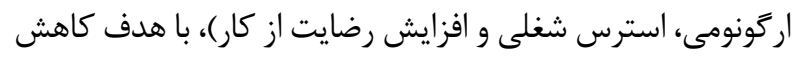

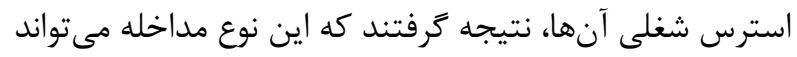

شغلى را بيمارى قرن بيستم دانست و جندى بعد سازمان

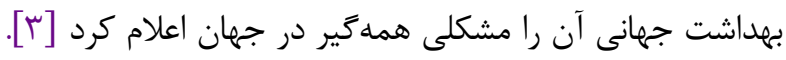

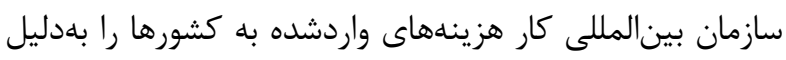

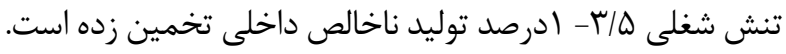

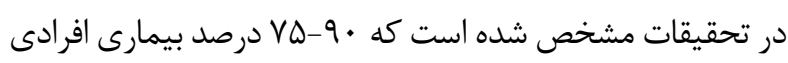

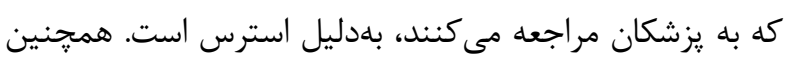

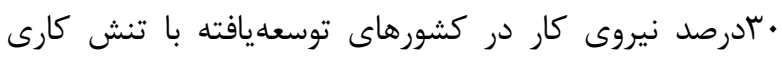

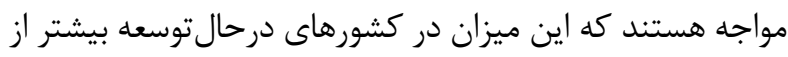

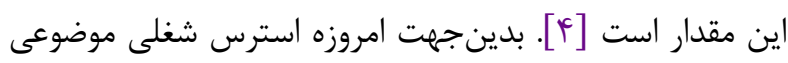

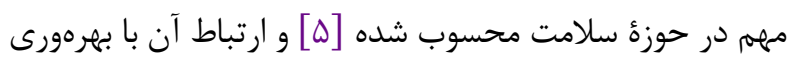

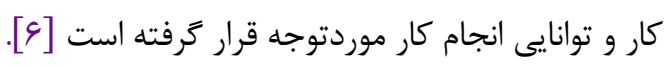
استرس شغلى موجب كاهش توانايى انجام كار نيز مى شود.

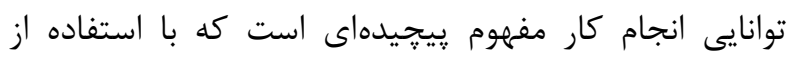

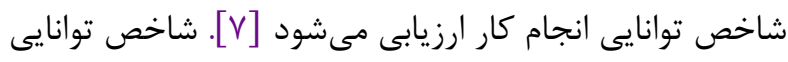

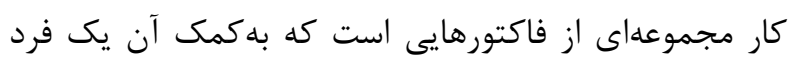

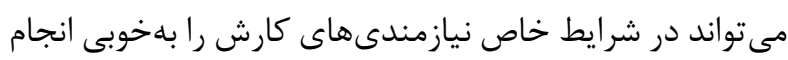

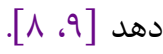
بر زيائٔ مطالعات كذشته، استرس شغلى يكى از مشكار

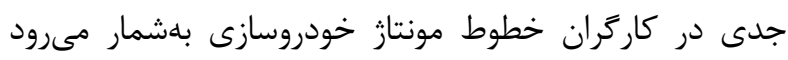

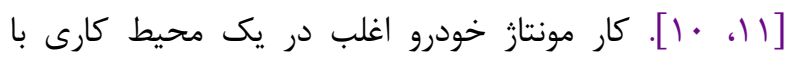
مشكلات فيزيكى مانند سروصدا، ارتعاشات و ماشينهاى خطرناك

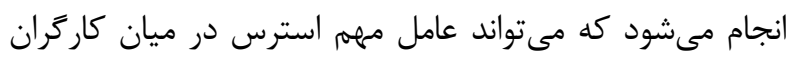

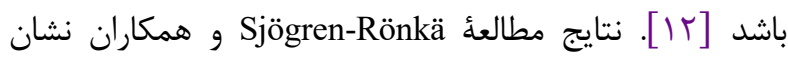
مى دهد، فشار روانى در محيط كار با توانايى شغلى رابطؤ تنكاتنكى مانى

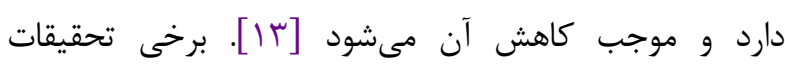

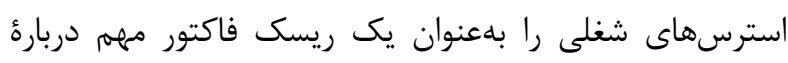

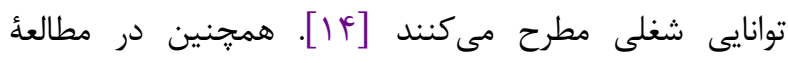
Kumasiro

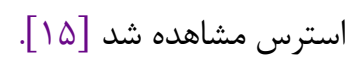
Yong و همكاران دريافتند، استرس ادراكشده ازسوى افراد

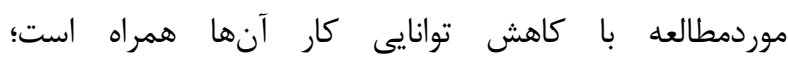

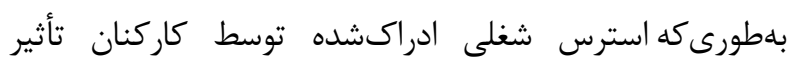

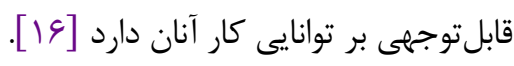

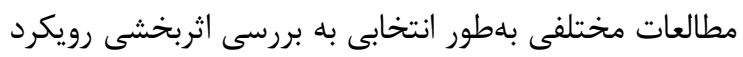

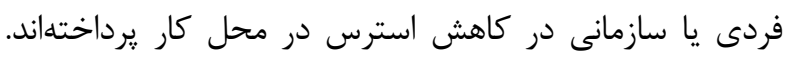

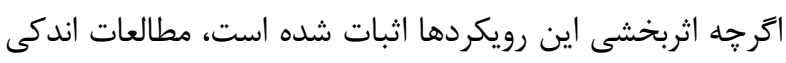
از روشهاى فوق بلهورت تركيبى در يك مداخله استفاده 
يزشكى شهيد بهشتى تهران با شناسٔ اخلاق IR.SBMU.PHNS.REC.1397.092 مداخلئ اصلى Ergo-JSI به مدت 1 هفته انجام شد؛ بديندليل كه اين طول مدت براى انجام برنامههاى آموزشى، بهويزه

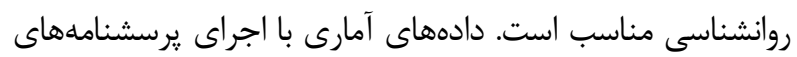

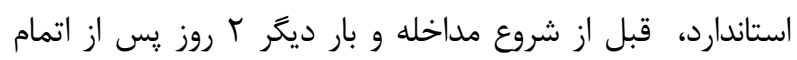

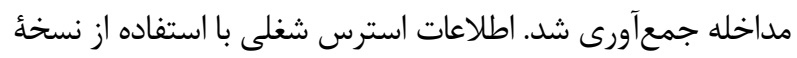

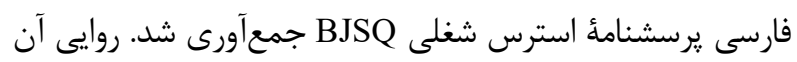

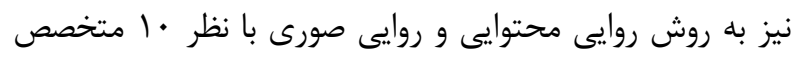

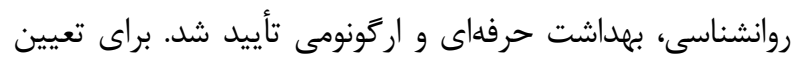

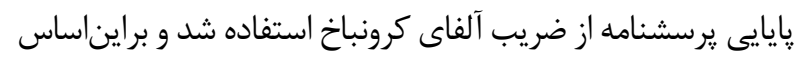

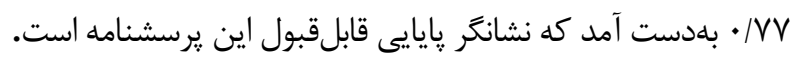

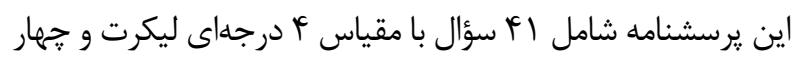

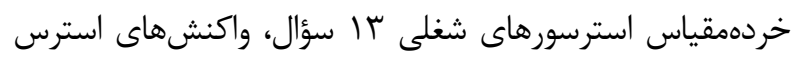

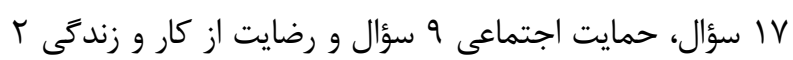

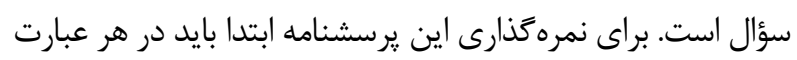

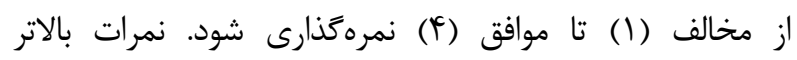
نشاندهنده استرس بيشتر است. درصورت لزوم، نمرءٔ معكوس مواف

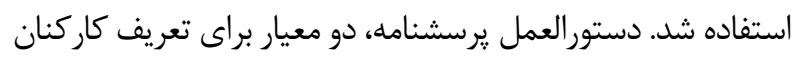
با استرس بالا، براساس BJSQ يِيشنهاد مى كند:

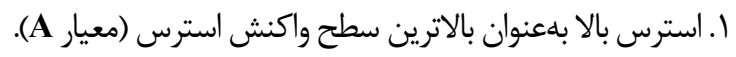

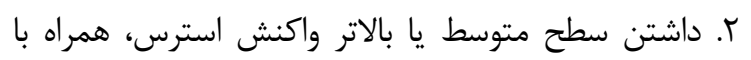
داشتن بالاترين ميزان استرسور شغلى يا كمترين حمايت اجتماعى دانى

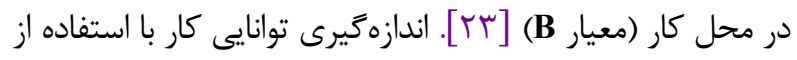

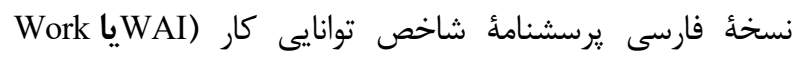
(Ability Index

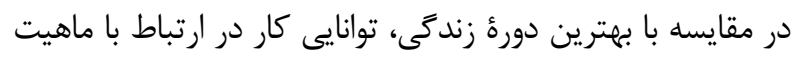

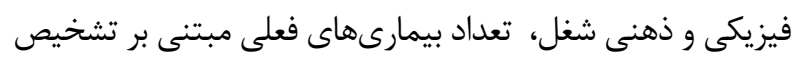

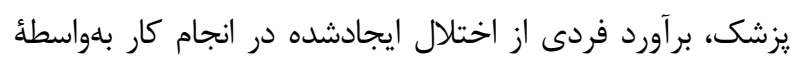

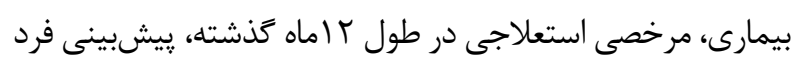

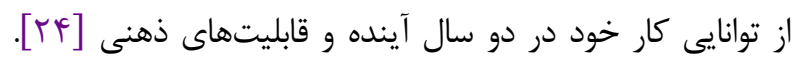
ترجمة يرسشنامة WAI به زبان فارسى و تعيين روايى و وِيايايى آن

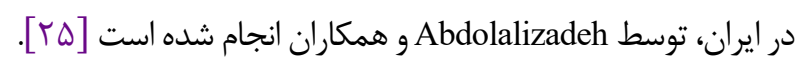

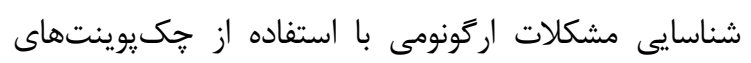

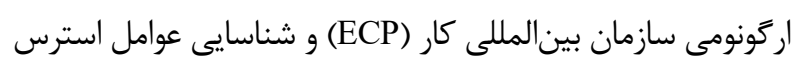

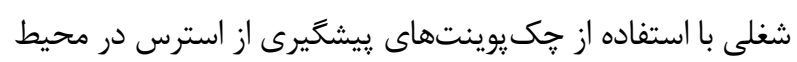

سبب كاهش خطرات شغلى، بهبود سلامت روانى و ايجاد رفاه

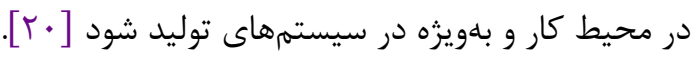
الر Cervai

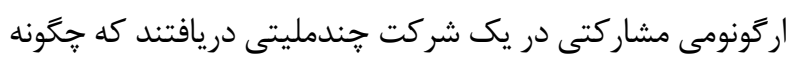

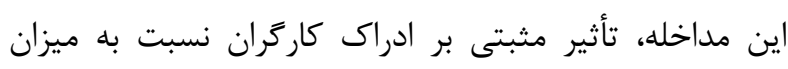

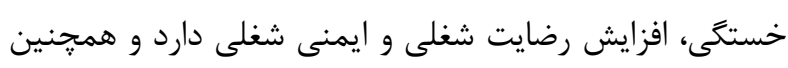

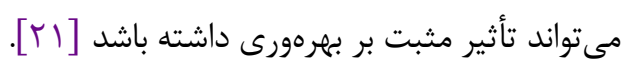

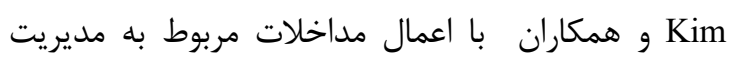

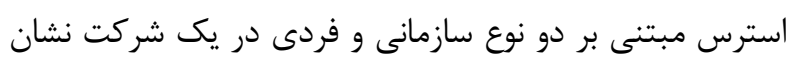

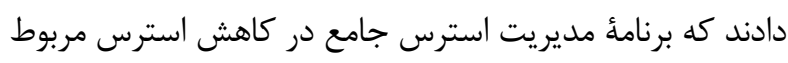

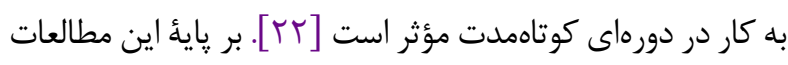

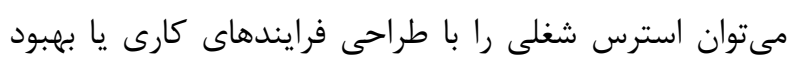

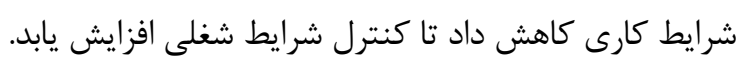
بررسى عامل استرس شغلى و شاخص توانايى كار شاغلان

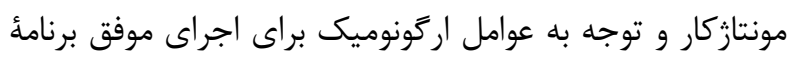

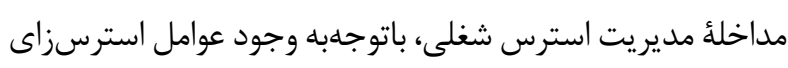
محيط كار در صنعت خودروسازى ضرورى است. باتبل بنابراين،

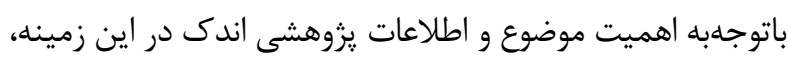

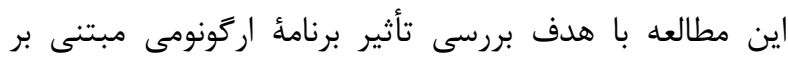

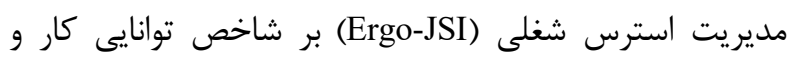
استرس شغلى مونتازكاران در يك صنعت توليد قطعات خودرو

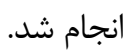

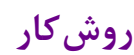

اين مطالعه از نوع مداخلهاى و بله روش بيش ريش آزمون-

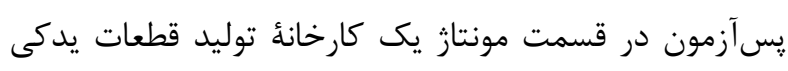

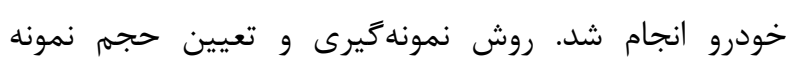

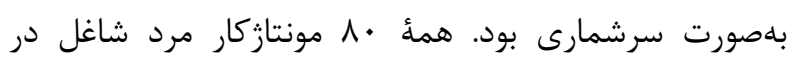

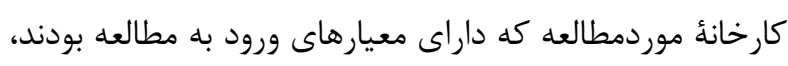

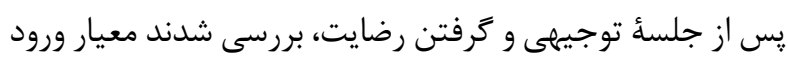

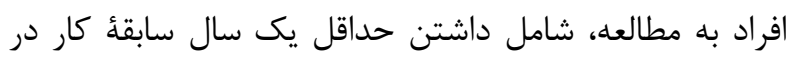

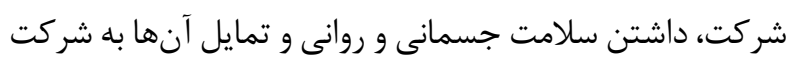

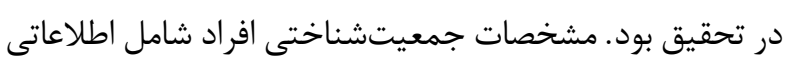

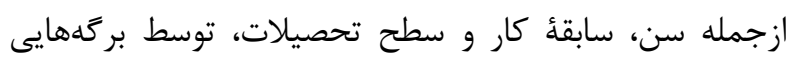

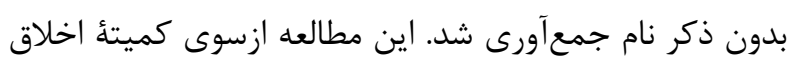

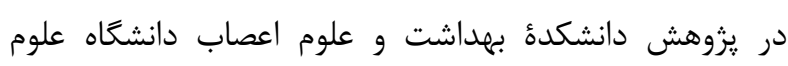


ابزارهاى دستى (امورد)، ايمنى ماشينآلات (امورد)، طراحى (آنى

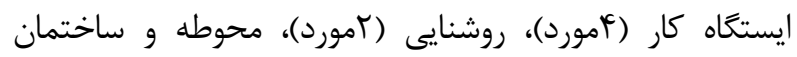

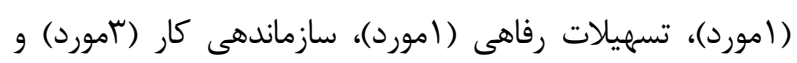

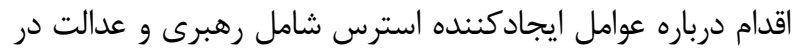

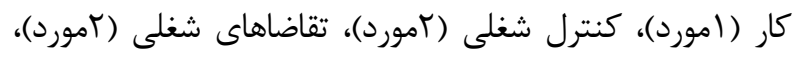

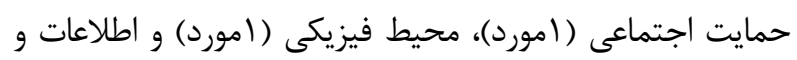
ارتباطات در محل (امورد) بود.

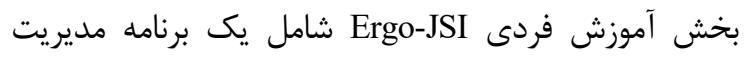

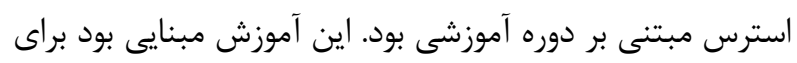

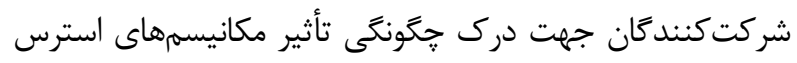

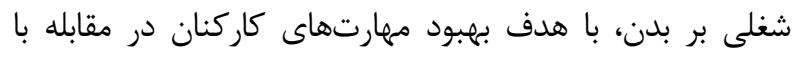

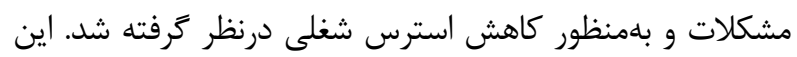

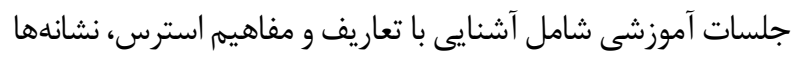
و علائم آن، عوامل ايجادكننده آن، مديريت زمان، مهارتهات إنهاى

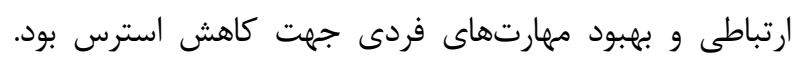

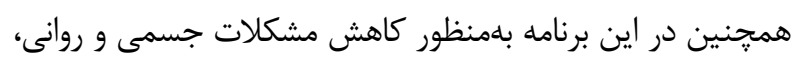

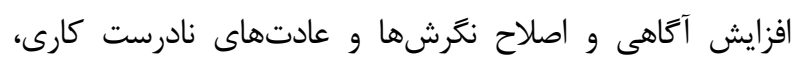

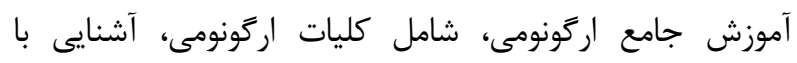

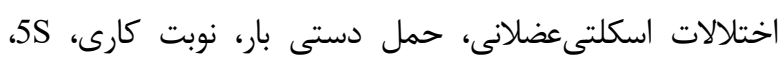

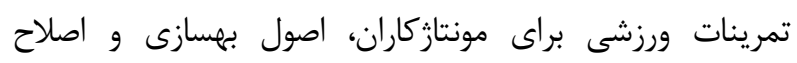

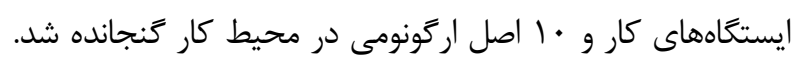

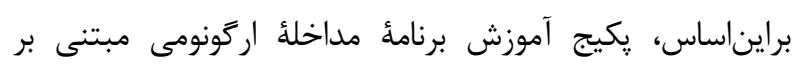

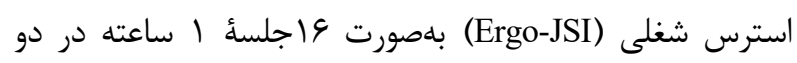

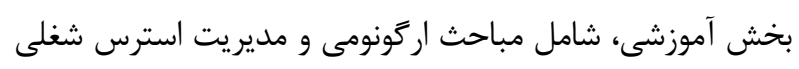
در قالب فايلهاى ياوريوينت شامل توضيحات كامل و تصاوير بسيار

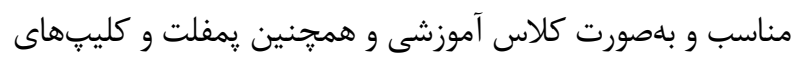
آموزشى طراحى و بركزار شد.

دادههاى بهدست آمده در اين تحقيق با نرمافزار يردازش شد. (SPSS Inc., Chicago, Ill., USA) TY تجزيلوتحليلها دادها به روشهاى آمارى ويلكاكسون، أزوجى و آزمون ساين تست در سطح معنادارى ه • • انجام شد.

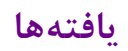

يافتههاى حاصل از اين تحقيق نشان داد كه بيشتر افراد

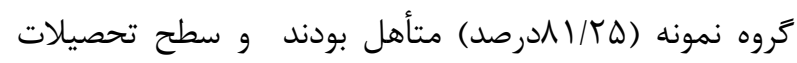
آنها (

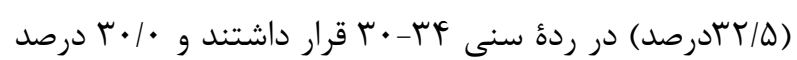

كار همين سازمان، يس از تهيئ نسخة بومى و مناسب محيط كار

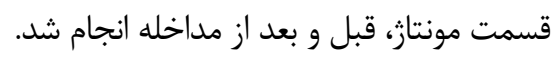

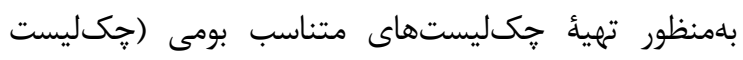

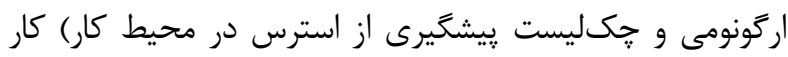

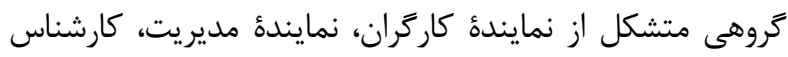

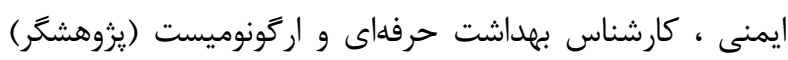

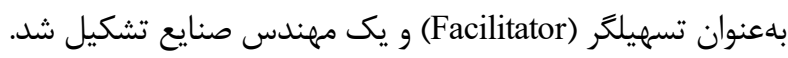

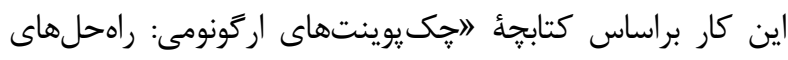

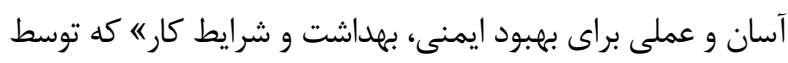

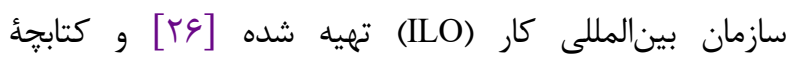

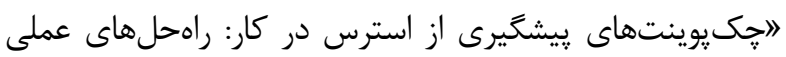

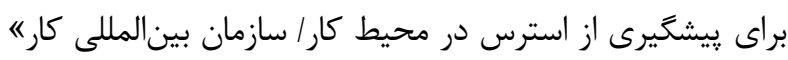

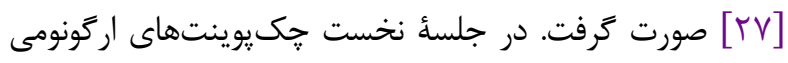

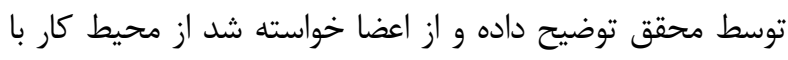

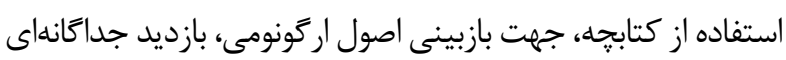

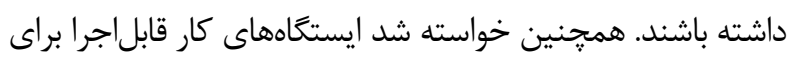

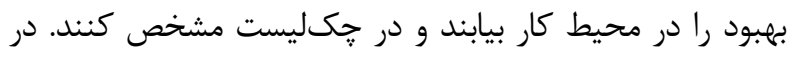

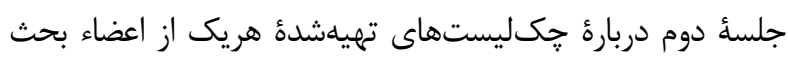

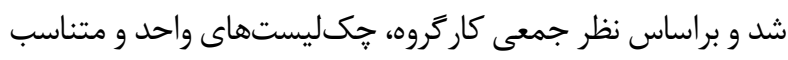

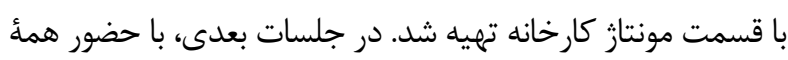

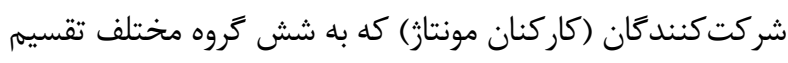

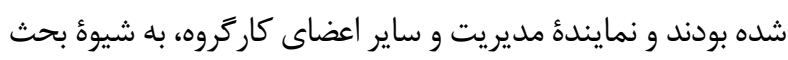
كروهى متمركز (FGD) از آنها خواسته شد تا جزئيات مشكلات

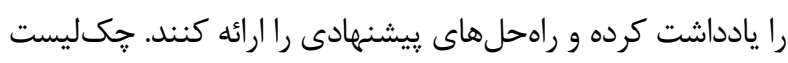

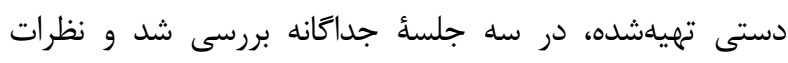

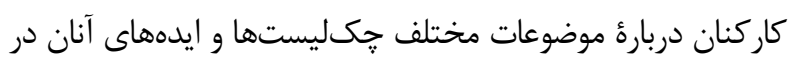

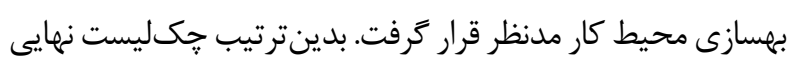

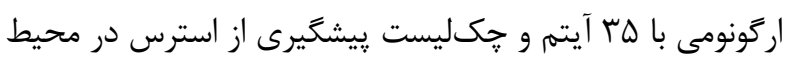

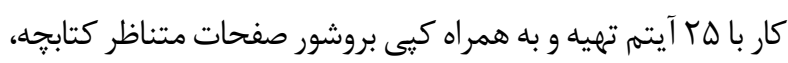

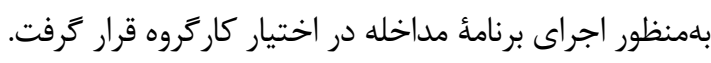

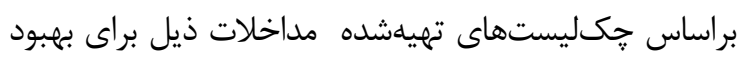

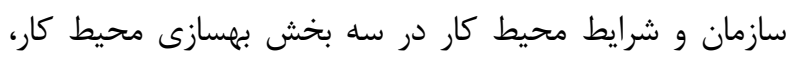

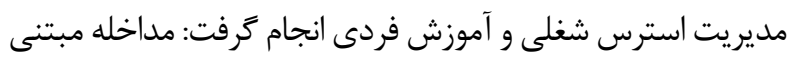

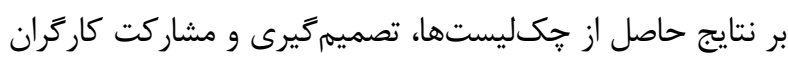

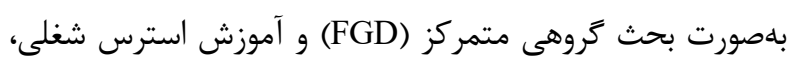

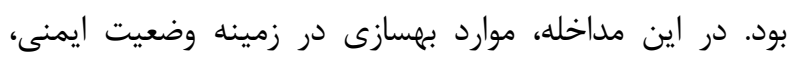

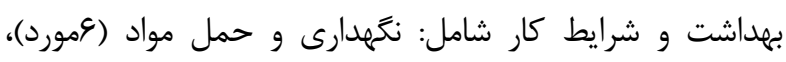


در جدول ا، توزيع فراوانى مشخصات فردى- شغلى كارگران آنها داراى جهار سال سابقه كار و كمتر بودند. ميانكَين و

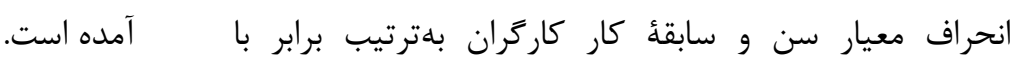

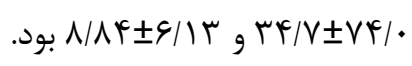

جدول ا. توزيع فر اوانى مشخصات فردى - شغلى كارَّران (•)

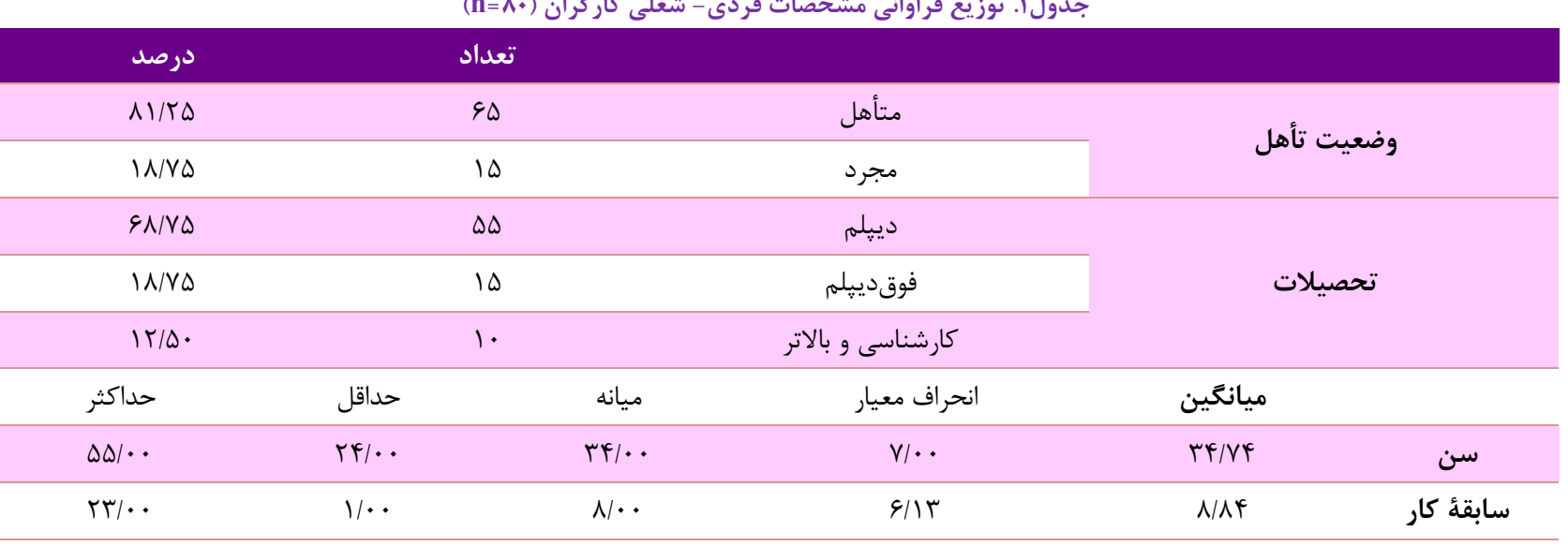

مىتواند بهدليل استفاده از مرخصى استعلاجى كارگران طى

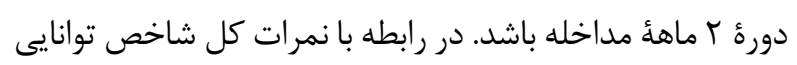
انجام كار كارگران بخش مونتاز، قبل و بعد از مداخلئ برنامئ Ergo-JSI

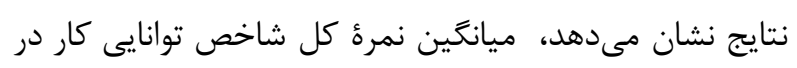

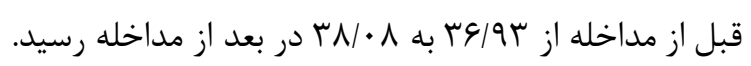

با توجه به جدول r، در حيطههاى توانايى كار فعلى، توانايى كار در رابطه با نيازهاى فيزيكى و ذهنى، بيمارىهاى فئ فعلى،

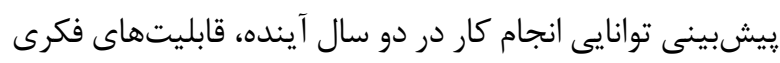
و ذهنى تفاوت آمارى معنادارى وجود داشت، اما در حيطة برآورد ميزان لطمه به كار بهدليل بيمارى، آسيب و مرخصى استعلاجى طى يك سال حذشته تفاوت آمارى معنادار نبود كه

Ergo-JSI جدول r. مقايسئ نمرات شاخص توانايى انجام كار به تفكيك حيطهها و كل در كارَّران قبل و بعد از مداخلهُ برنامئ

\begin{tabular}{|c|c|c|c|c|}
\hline \multirow[b]{2}{*}{ P-value } & \multicolumn{2}{|c|}{ 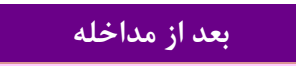 } & 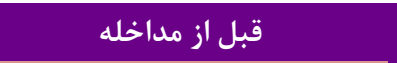 & \multirow[b]{2}{*}{ شاخص توانايى انجام كار به تفكيك حيطهها و كل } \\
\hline & انحراف & 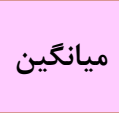 & انحر اف معيار & \\
\hline$*<\cdot 1 \cdot \cdot 1$ & $\cdot 194$ & N/9 & $1 / 19$ & توانايى كار فعلى در ارتباط با بهترين زمان زندكى \\
\hline$* \cdot 1 \cdot \cdots 1$ & $1 / 0$ & $1 / 19$ & 1/r & توانايى كار در رابطه با نيازهاى فيزيكى و ذهنى شغل \\
\hline$*<\cdot 1 \cdot \cdot 1$ & $r / l V$ & $\varphi / \Delta \Lambda$ & t/Tt & بيمارىهاى فعلى تشخيص دادهشده \\
\hline$* \cdot / \cdot \wedge r$ & $\cdot / 9$ & $\Delta / \Delta \Lambda$ & $\cdot 190$ & بر آورد ميزان لطمه به كار بهدليل بيمارى و آسيب \\
\hline$* \cdot / 999$ & $\cdot \operatorname{lor}$ & $r / V \Delta$ & $\cdot / \Delta T$ & مرخصى استعلاجى طى يك سال كذشته \\
\hline$* \cdot 1 \cdot \cdot 1$ & $1 / 91$ & $9 / 1$. & $r / \cdot r$ & ييشبينى توانايى انجام كار در دو سال آينده \\
\hline$*<\cdot 1 \cdot \cdot 1$ & $\cdot / 94$ & r/gY & $\cdot \mid \Lambda \Lambda$ & قابليتهاى فكرى و ذهنى \\
\hline$* *<+\mid \cdot 1$ & $r / V I$ & $r \Lambda / \wedge$ & $r / 9 r$ & نمرءٔ كل شاخص توانايى كار \\
\hline 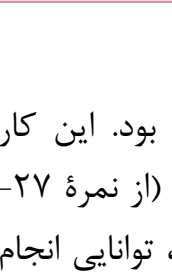 & 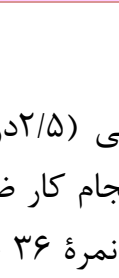 & 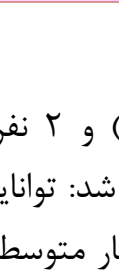 & 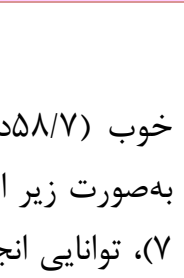 & 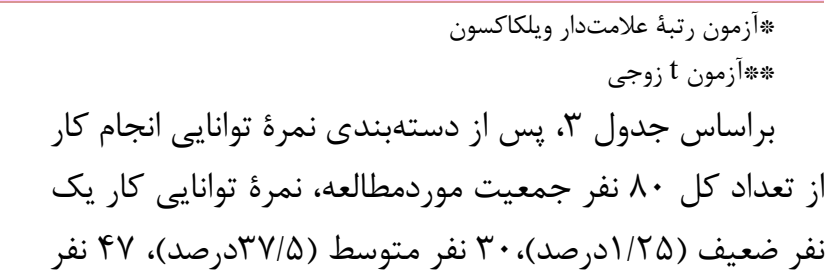 \\
\hline
\end{tabular}


كار خوب (از نمرة بץ-

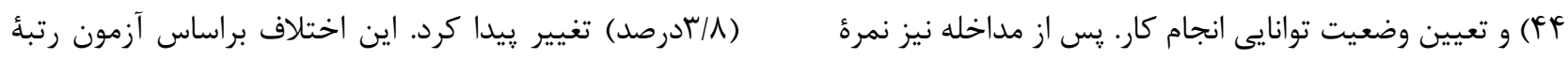

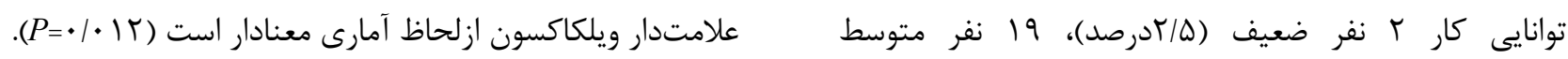

Ergo-JSI جدول r. مقايسَٔ سطح توانايى انجام كار در كاركران قبل و بعد از مداخللَ برنامه

\begin{tabular}{|c|c|c|c|c|}
\hline P-value & 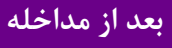 & 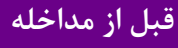 & \multicolumn{2}{|c|}{ وضعيت نمره شاخص توانايى انجام كار } \\
\hline \multirow{8}{*}{$* \cdot / \cdot 1 r$} & r & 1 & 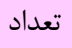 & \multirow{2}{*}{ ضعيف } \\
\hline & $r / \Delta$ & $1 / T \Delta$ & 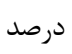 & \\
\hline & 19 & r. & تعداد & \multirow{2}{*}{ 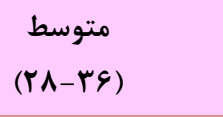 } \\
\hline & $r \mu / \Lambda$ & $r V / Q$ & 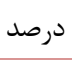 & \\
\hline & $\Delta \varphi$ & fr & تعداد & \multirow{2}{*}{$\begin{array}{c}\text { خوب (rV-Fr) } \\
\text { (rV }\end{array}$} \\
\hline & $\vee \cdot$ & $\Delta \Lambda / V$ & 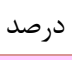 & \\
\hline & r & r & 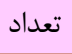 & \multirow{2}{*}{$\begin{array}{c}\text { عالى } \\
(f f-f q)\end{array}$} \\
\hline & r/A & $T / Q$ & درصد & \\
\hline
\end{tabular}

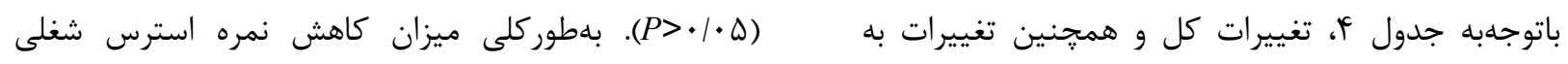

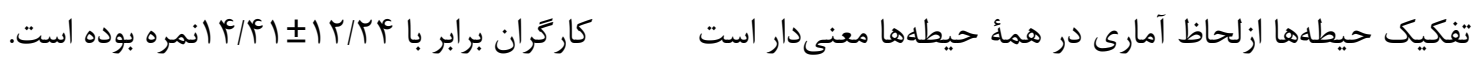

جrgo-JSI جدول F. مقايسُٔ نمرات استرس شغلى به تفكيك حيطهها و كل در كارَّران قبل و بعد از مداخلهُ برنامهُ

\begin{tabular}{|c|c|c|c|c|c|}
\hline \multirow[b]{2}{*}{ P-value } & \multicolumn{2}{|c|}{ بعد از مداخله } & \multicolumn{2}{|c|}{ قبل از مداخله } & \multirow[b]{2}{*}{ استرس شغلى به تفكيك حيطهها و كل } \\
\hline & انحراف & ميانگين & انحراف معيار & ميانغين & \\
\hline$*<\cdot 1 \cdot \cdot 1$ & $r / \mathcal{F V}$ & $r F / \cdot \Delta$ & e/TV & rN/V & ن نيازهاى شغل \\
\hline$* * * 1 \cdots 1$ & $91 .$. & rN/qF & $1 \cdot 1 \cdot 9$ & $\mathrm{rV} / \cdot \mathrm{q}$ & واكنش هاى استرس \\
\hline
\end{tabular}

\begin{tabular}{|c|c|c|c|c|c|c|}
\hline$*<\cdot 1 \cdot \cdot 1$ & $1 / 4 V$ & V/9r & $r / \cdot V$ & N/Vr & حمايت سريرستان & \\
\hline$* \cdot / \cdot r$ & $1 / 49$ & V/rT & $1 / 99$ & $V(9)$ & حمايت همكاران & منابع شغل \\
\hline$*<\cdot 1 \cdot \cdot 1$ & $1 / r \mu$ & $F / 19$ & $1 / 91$ & $r / 9 \Lambda$ & حمايت خانواده، دوستان و ساير & \\
\hline
\end{tabular}

نمرة كل

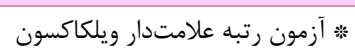

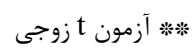

شغلى (كمترين حمايت اجتماعى در محل كار ) (معيار B) براى

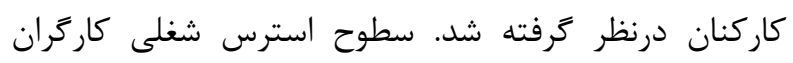

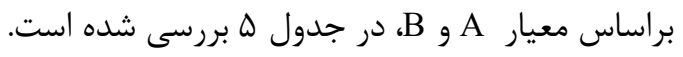

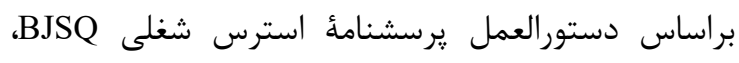

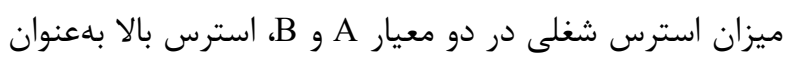

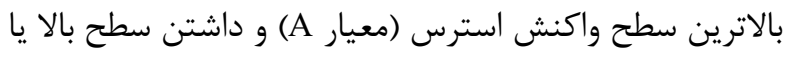

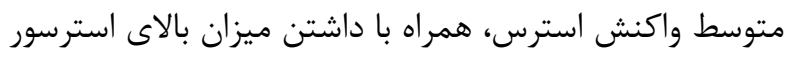


جدول ه. مقايسئ استرس شغلى كاركران قبل و بعد از مداخله برنامهُ Ergo-JSI بر مبناى معيار A و B

\begin{tabular}{|c|c|c|c|c|}
\hline P-value & ل درصد & 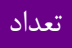 & \multicolumn{2}{|c|}{ سطح استرس شغلى } \\
\hline \multirow{6}{*}{$*<\cdot|\cdot|$} & $r \cdot 1 \cdot$. & 19 & داراى سطح استرس خيلى بالا & \multirow{3}{*}{ براساس معيار A قبل از مداخله } \\
\hline & rG/Ta & $r q$ & داراى سطح استرس متوسط به بالا & \\
\hline & $r \mu / V Q$ & $r \Delta$ & داراى سطح استرس متوسط به پايين & \\
\hline & $1 / 4$. & 1 & داراى سطح استرس خيلى بالا & \multirow{3}{*}{ براساس معيار A بعد از مداخله } \\
\hline & $1 \cdot 1 \cdot$ & $\wedge$ & داراى سطح استرس متوسط به بالا & \\
\hline & $\Lambda N / \Lambda$ & M & داراى سطح استرس متوسط به پايين & \\
\hline \multirow{4}{*}{$*<\cdot \mid \cdot \cdot 1$} & TN/VD & r & داراى سطح استرس بالا & \multirow{2}{*}{ براساس معيار B قبل از مداخله } \\
\hline & $V I / r \Delta$ & $\Delta V$ & داراى سطح استرس متوسط به پايين & \\
\hline & $1 / \pi \Delta$ & 1 & داراى سطح استرس بالا & \multirow{2}{*}{ براساس معيار B بعد از مداخله } \\
\hline & $9 \Lambda / V \Delta$ & vq & داراى سطح استرس متوسط به پايين & \\
\hline
\end{tabular}

قرار كرفت. درواقع ميانكين نمره شاخص توانيى كار كاركران مونتازكار

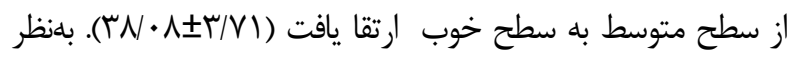

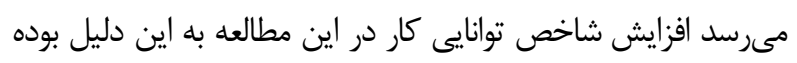

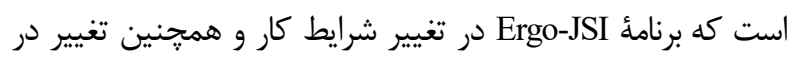

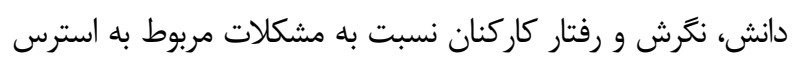

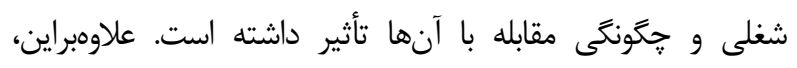
اركونوميكترشدن وضعيت محيط كار بادليل كاهش موانع استرسز إنسا

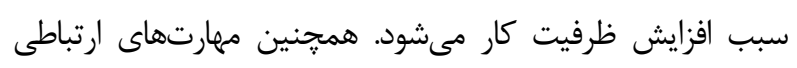
آموزش دادهشه در Ergo-JSI به كاركنان كمك مى كند تا بتوانند احساسات و افكار خود را بهشكلى قاطع به همكاران و سريرستان

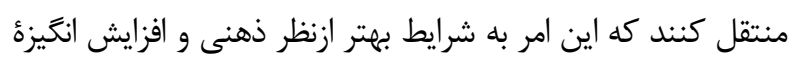
شغلى منجر مىشود. در يزوهش Purnawati بلمنظور تعيين تأثير استفاده از

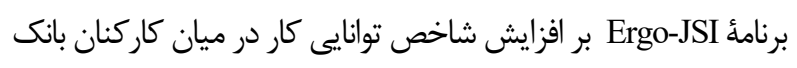

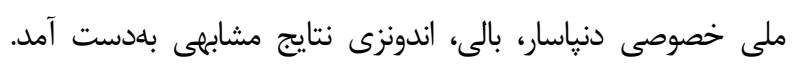
همجنين ميانكين WAI از

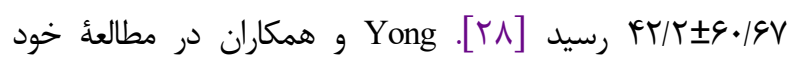
بلمنظور بررسى تأثير استرس ادراكشده بر توانايى كار در مر ميان

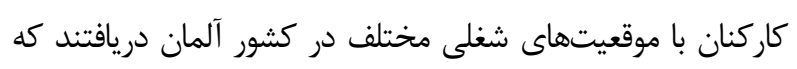
استرس ادراكشده توسط افراد موردمطالعه، با كاهش توانايى كار آنها همراه بود؛ بلهورى كه استرس شغلى ادراكشده توسط كاركنان تأثير

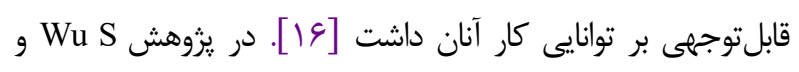

براساس جدول Fا، مطابق معيار A (واكنشهاى استرس) قبل از

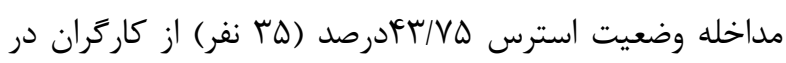

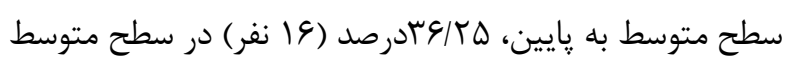

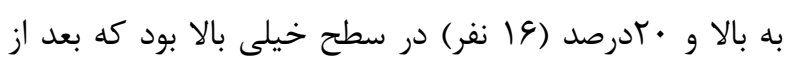

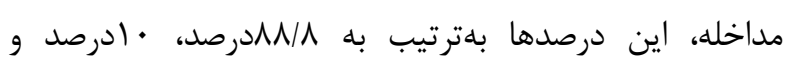

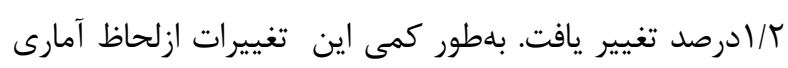

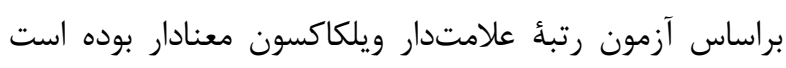

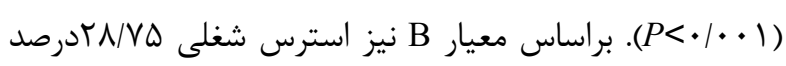

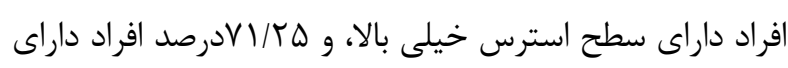

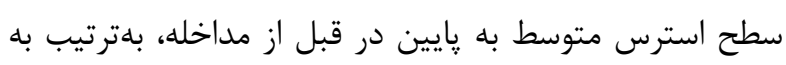

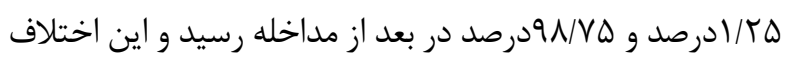
ازلحاظ آمارى براساس آزمون رتبهُ علامت دار ويلكاكسون معنادار

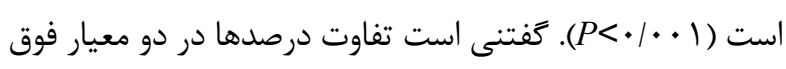

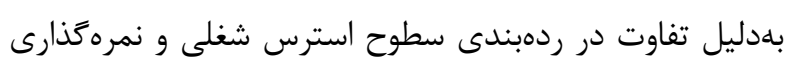
براساس نقاط برش در دو معيار است.

\section{بحث}

نتايج يزوهش حاضر نشان مى دهد، برنامؤ Ergo-JSI بر شاخص

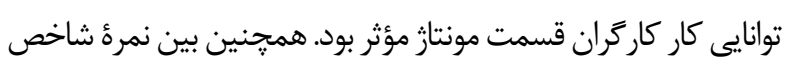

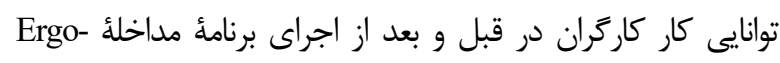

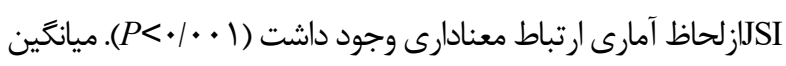

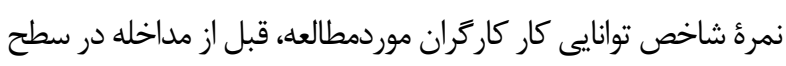

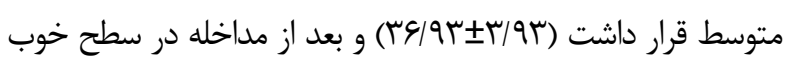


سطح واكنش استرس (معيار A) و داشتن سطح متوسط يا بالاتر

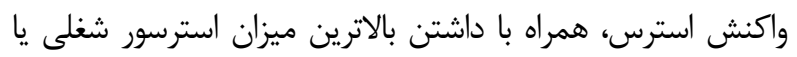

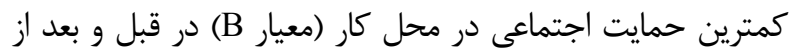

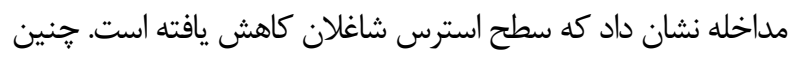

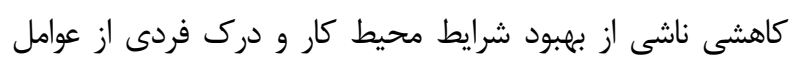

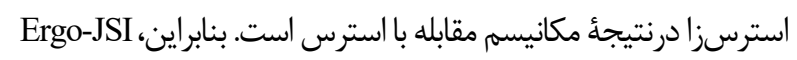

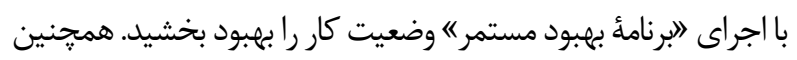

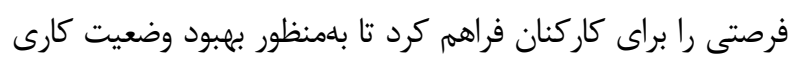

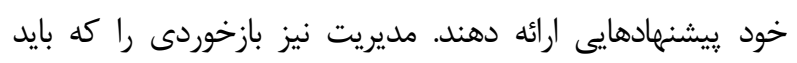
باشكلى مستقيم در برنامة مديريت استرس شغلى اجرا شود، ارائه كرد. اين امر بر وضعيت كارى و ديدگاه سازمانى كاركنان تأثيركذار بود و

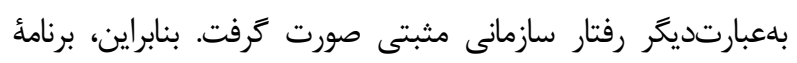

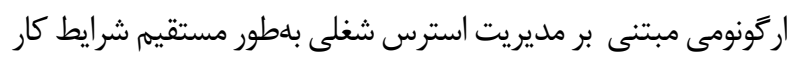

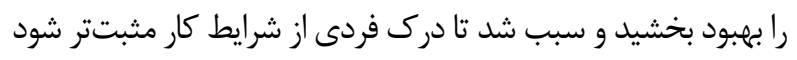
و درنتيجه عوامل استرسزا كاهش يابد.

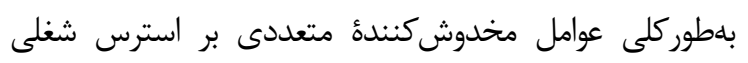

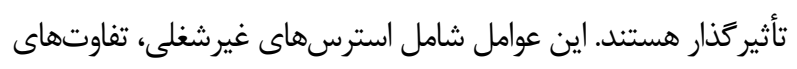

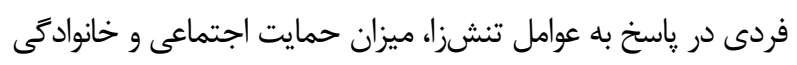

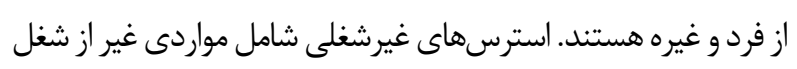

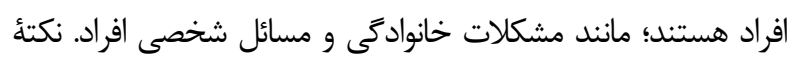

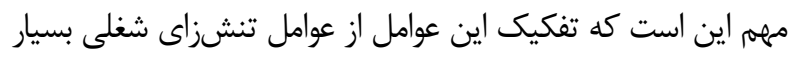
مشكل است؛ زيرا بلهدت به هم آميختهاند و بر هم تأثير مى كذارند.

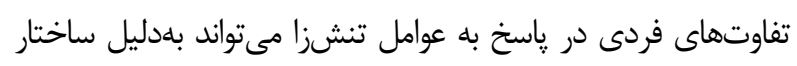

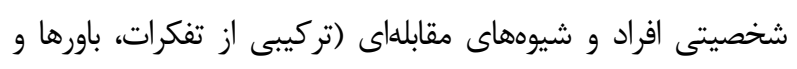

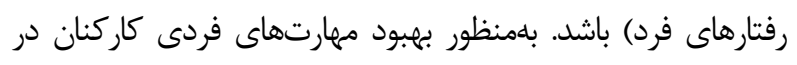

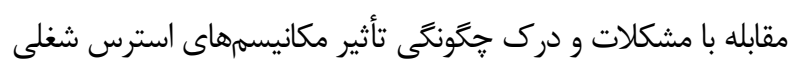
بر بدن، بخش منحصربهفرد Ergo-JSI شامل يك برنامئ مديريت

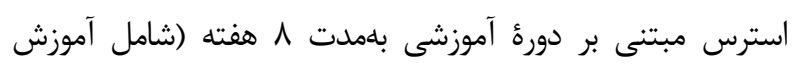

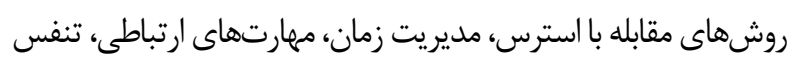

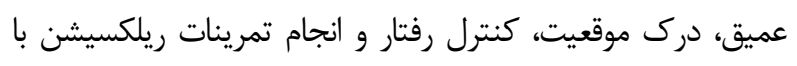

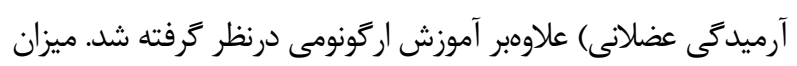

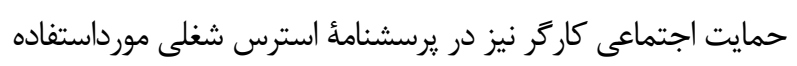
شامل حمايت سريرستان (ب سؤال)، حمايت همكاران (BJSQ)

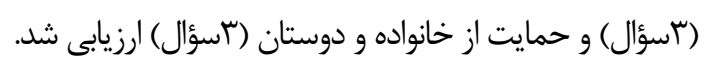

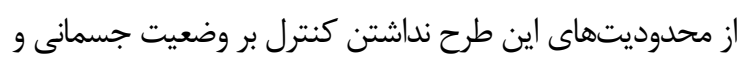
روانى كاركنان موردمطالعه در حين تكميل يرسشنامهها، كنترلنكردن برخى متغيرهاى مخدوشكر ازجمله وضعيت اقتصادى كشور و نوسانات نمان

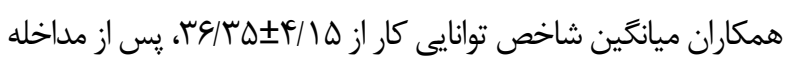

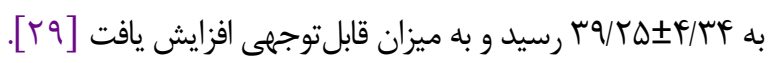

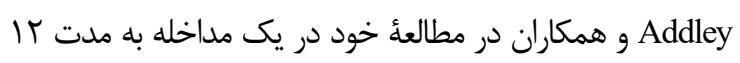

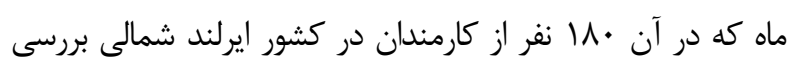

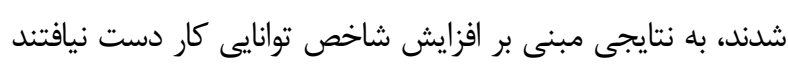

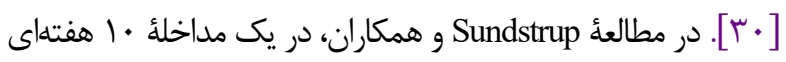

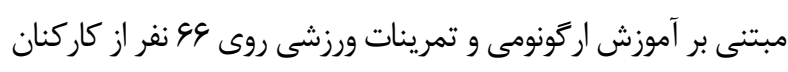

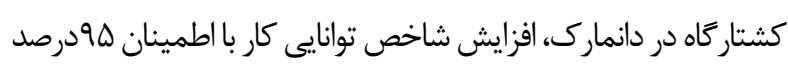

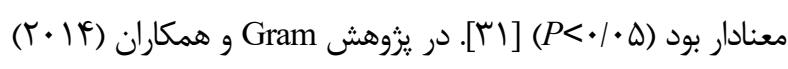

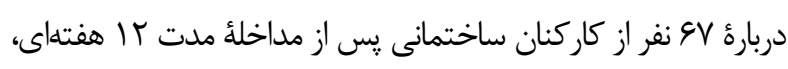

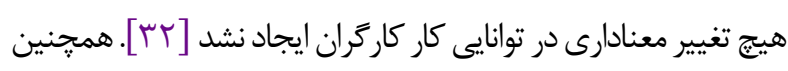

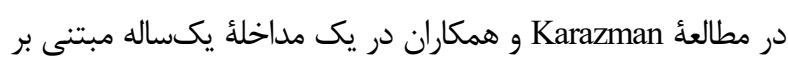

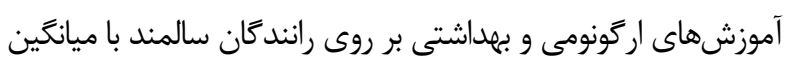

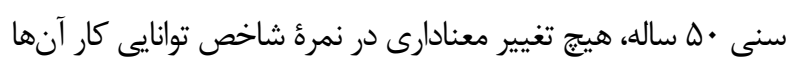

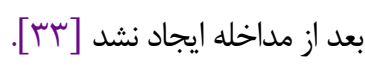

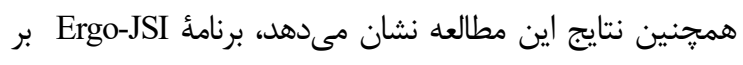

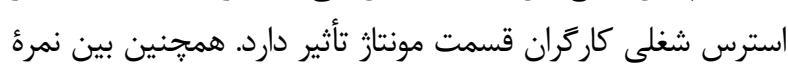

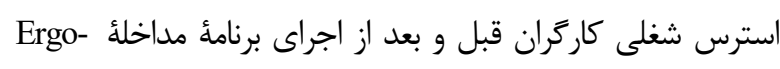
JIJSI

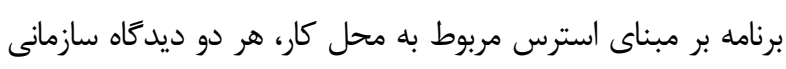

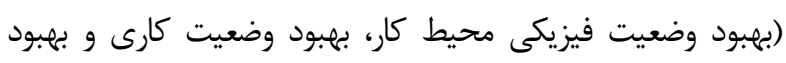

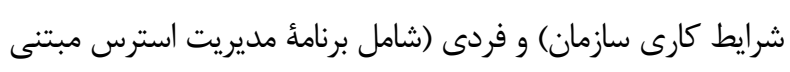

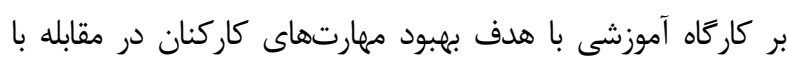

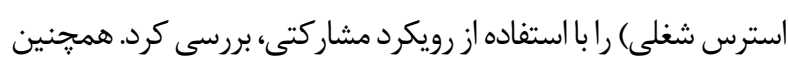

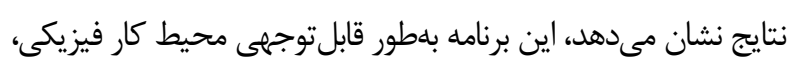

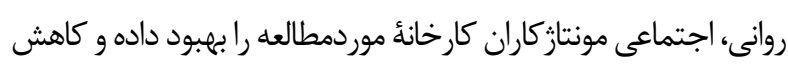
استرس آنها را بههمراه داشته است. Purnawati

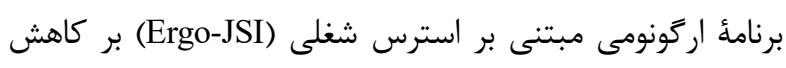

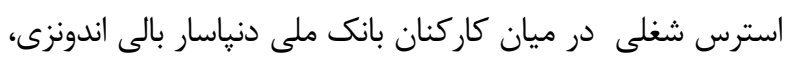

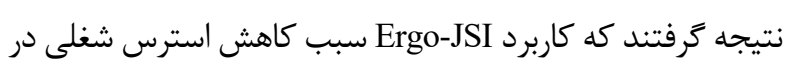

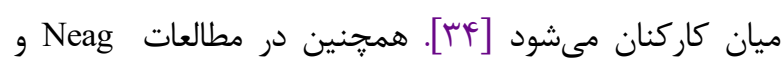

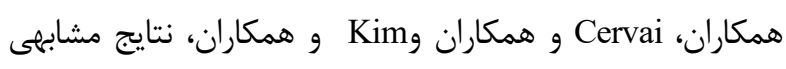

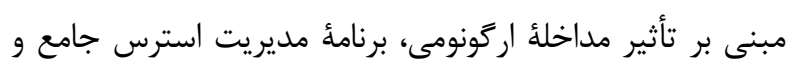

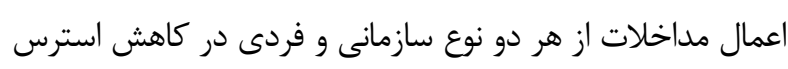

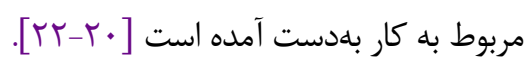

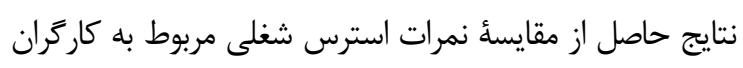

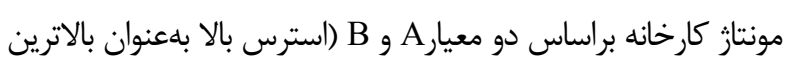


مختلف انجام گيرد. علاوهبراين، مديريت شركت مىتواند ضمن

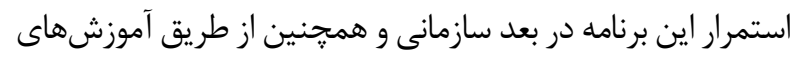

مديريت استرس در بعد فردى، اين فرآيند مداخلهاى را بهطور

ادوارى ادامه دهد تا اثربخشى و مزاياى حاصل از اجراى برنامئ Ergo-JSI شود و سازمان و كاركنان از آن بجرهمند شوند.

$$
\text { تقدير و تشكر }
$$

نويسند كان مقاله از مديران محترم و كاركنان گرامى و زحمتكش شركت توليد قطعات خودرو كه در انجام اين تحقيق مساعدت و همكارى كردند، صميمانه تشكر مى كنند.

$$
\text { تعارض منافع }
$$$$
\text { بين نويسندگان تعارضى در منافع وجود ندارد. }
$$

$$
\text { منابع مالى }
$$

منابع مالى اين مطالعه توسط نويسندكان تامين شده است.

\section{References}

1. Mojoyinola JK. Effects of job stress on health, personal and work behaviour of nurses in public hospitals in Ibadan Metropolis, Nigeria. Studies on Ethno-Medicine. 2008 Jul 1;2(2):143-8.

[DOI:10.1080/09735070.2008.11886326]

2. National Institute for Occupational Safety and Health. Exposure to stress. Occupational hazards in hospitals, DHHS. Centers for desease cntrol and prevention. [Internet]. http://www.cdc.gov/NIOSH

3. Khosravi M. Examine job stressors librarians working in academic libraries Ministry of Science. Research and Technology, Tehran, from their perspective, research projects, Information and Documentation Center of Iran, Tehran. 2004.

4. Hoel H, Sparks K, Cooper CL. The cost of violence/stress at work and the benefits of a violence/stress-free working environment. Geneva: International Labour Organization. 2001 Jan 1;81.

5. Knezevic B, Milosevic M, Golubic R, Belosevic L, Russo A, Mustajbegovic J. Work-related stress and work ability among Croatian university hospital midwives. Midwifery. 2011 Apr 1;27(2):146-53. [DOI:10.1016/j.midw.2009.04.002] [PMID]

6. Karasek R, Theorell T. Healthy Work Basic Books. New York. 1990; 990:54.

7. Goedhard RG, Goedhard WJ. Work ability and perceived work stress. Int Congr 2005 Jun 1 (Vol. 1280, pp. 79-83). Elsevier. [DOI:10.1016/j.ics.2005.02.051]

$$
\begin{aligned}
& \text { بازار ارز بود كه تأثير مستقيمى بر وضعيت اقتصادى صنايع و در } \\
& \text { يرداخت بهموقع حقوق كاركران داشت و خارج از كنترل يزوهشكر بود. بودئ } \\
& \text { نتيجه كيرى } \\
& \text { مطالعهُ حاضر نشان مىدهد، استفاده از برنامهٔ مداخلهُ مديريت } \\
& \text { استرس Ergo-JSI، با رويكرد فردى و سازمانى بر كاهش استرس } \\
& \text { كارگران قسمت مونتاز يك كارخانهُ توليد قطعات خودرو، نتايج } \\
& \text { مثبتى را بلهدنبال داشته است. پيس از مداخله، ميزان توانايى كار }
\end{aligned}
$$

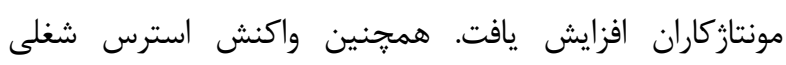

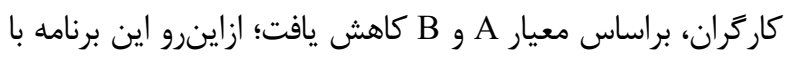

$$
\begin{aligned}
& \text { رويكرد يكيارجهأ خود در بهبود سلامت روانى كاركنان مؤثر است و }
\end{aligned}
$$

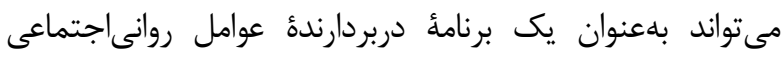

$$
\begin{aligned}
& \text { اثربخش در محيط كار مطرح باشد. درنهايت نيز بر افزايش توانايى } \\
& \text { انجام كار و كاهش استرس شغلى كاركنان بخش صنعت مؤثر است. } \\
& \text { براساس يافتههاى اين مطالعه، ييشنهاد مىشود مطالعات مشابه با } \\
& \text { اين يزوهش و با تعداد نمونههاى بيشتر در شركتها و ادارات }
\end{aligned}
$$

8. Ilmarinen J, Tuomi K, Klockars M. Changes in the work ability of active employees over an 11-year period. Scand J Work Environ Health. 1997 Jan 1:49-57.

9. Ilmarinen J, Tuomi $\mathrm{K}$, Eskelinen L, Nygård $\mathrm{CH}$, Huuhtanen P, Klockars M. Background and objectives of the Finnish research project on aging workers in municipal occupations. Scand J Work Environ Health. 1991 Jan 1:7-11.

10. Kumlin L, Latscha G, Orth-Gomér K, Dimberg L, Lanoiselee C, Simon A, Eriksson B, Coeur Study Group. Marital status and cardiovascular risk in French and Swedish automotive industry workers-cross sectional results from the Renault-Volvo Coeur study. J. Intern. Med. 2001 Apr; 249(4):315-23. [DOI:10.1046/j.13652796.2001.00817.x] [PMID]

11. Oleske DM, Neelakantan J, Andersson GB, Hinrichs BG, Lavender SA, Morrissey MJ, Zold-Kilbourn P, Taylor E. Factors affecting recovery from work-related, low back disorders in autoworkers. Arch Phys Med Rehabil. 2004 Aug 1;85(8):1362-4. [DOI:10.1016/j.apmr.2003.11.021] [PMID]

12. Kvarnström S. Stress prevention for blue-collar workers in assembly-line production. International Labour Organization; 1997.

13. Sjögren-Rönkä T, Ojanen MT, Leskinen EK, Mustalampi ST, Mälkiä EA. Physical and psychosocial prerequisites of functioning in relation to work ability and general subjective well-being among office workers. Scand. J. Work Environ. Health. 2002 Jun 1:184-90. [DOI:10.5271/sjweh.663] [PMID] 
14. Geukes M, van Aalst MP, Nauta MC, Oosterhof H. The impact of menopausal symptoms on work ability. Menopause Int. 2012 Mar 1;19(3):278-82. [DOI:10.1097/gme.0b013e31822ddc97] [PMID]

15. Kumasiro M. The improvement of stress moods and the increase in negative emotions toward work have a major impact on declines in WAI scores: The first WAI research in Japan. In4 th ICOH Conference on Ageing and Work. Krakow: Jagiellonian Univ 2002 (p. 50).

16. Yong M, Nasterlack M, Pluto RP, Lang S, Oberlinner C. Occupational stress perception and its potential impact on work ability. Work. 2013 Jan 1;46(3):347-54. [DOI:10.3233/WOR-121556] [PMID]

17. Van der Klink JJ, Blonk RW, Schene AH, Van Dijk FJ. The benefits of interventions for work-related stress. Am. J. Public Health. 2001 Feb;91(2):270. [DOI:10.2105/AJPH.91.2.270] [PMID] [PMCID]

18. Shimazu A, Umanodan R, Schaufeli WB. Effects of a brief worksite stress management program on coping skills, psychological distress and physical complaints: a controlled trial. Int. Arch. Occup. Environ. Health. 2006 Oct; 80(1):60-9. [DOI:10.1007/s00420-006-0104-9] [PMID]

19. Helali F, Lönnroth EC, Shahnavaz H. Participatory ergonomics intervention in an industrially developing country-a case study. Int J Occup Saf Ergon. 2008 Jan $1 ; 14(2): 159-76$.

[DOI:10.1080/10803548.2008.11076760] [PMID]

20. Neag PN, Ivascu L, Mocan A, Draghici A. Ergonomic intervention combined with an occupational and organizational psychology and sociology perspectives in production systems. InMATEC Web of Conferences 2020 (Vol. 305, p. 00031). EDP Sciences. [DOI:10.1051/matecconf/202030500031]

21. Cervai S, Polo F. The impact of a participatory ergonomics intervention: the value of involvement. Theor Issues Ergon Sci. 2018 Jan 2;19(1):55-73. [DOI:10.1080/1463922X.2016.1274454]

22. Kim SA, Suh C, Park MH, Kim K, Lee CK, Son BC, Kim JH, Lee JT, Woo KH, Kang K, Jung H. Effectiveness of a comprehensive stress management program to reduce work-related stress in a medium-sized enterprise. Ann. Occup. Environ. Med 2014 Dec;26(1):1-9. [DOI:10.1186/2052-4374-26-4] [PMID] [PMCID]

23. Tsutsumi A, Shimazu A, Eguchi H, Inoue A, Kawakami N. A Japanese Stress Check Program screening tool predicts employee long-term sickness absence: a prospective study. J. Occup health. 2017:17-0161.

24. Ilmarinen J. The work ability index (WAI). Occup Med (Lond). 2007 Mar 1;57(2):160.

[DOI:10.1093/occmed/kqm008]

25. Abdolalizadeh M, Arastoo AA, Ghsemzadeh R, Montazeri A, Ahmadi K, Azizi A. The psychometric properties of an Iranian translation of the Work Ability Index (WAI) questionnaire. J. Occup. Rehabil. 2012 Sep;22(3):401-8. [DOI:10.1007/s10926-012-9355-3] [PMID]
26. International Ergonomics Association. Ergonomic checkpoints: practical and easy-to-implement solutions for improving safety, health and working conditions. International Labour Organization; 2010.

27. International Labour Office. Stress prevention at work checkpoints: Practical improvements for stress prevention in the workplace. International Labour Office; 2012.

28. Purnawati, S. Job stress management program (Ergo-JSI) Improving Work Ability Index (WAI) employees Bank of the "X" National private Bank in Denpasar bali. In Proceeding of the 2015 National Seminar and Congress of PEI (pp. I-1).E-29. Atma Jaya University Yogyakarta.

29. Wu S, Li J, Wang M, Wang Z, Li H. Intervention on occupational stress among teachers in the middle schools in China. Stress and Health: Journal of the International Society for the Investigation of Stress. 2006 Dec;22(5):329-36. [DOI:10.1002/smi.1108]

30. Addley K, Boyd S, Kerr R, McQuillan P, Houdmont J, McCrory M. The impact of two workplace-based health risk appraisal interventions on employee lifestyle parameters, mental health and work ability: results of a randomized controlled trial. Health Educ Res. 2014 Apr 1;29(2):247-58. [DOI:10.1093/her/cyt113] [PMID]

31. Sundstrup E, Jakobsen MD, Brandt M, Jay K, Persson R, Aagaard P, Andersen LL. Workplace strength training prevents deterioration of work ability among workers with chronic pain and work disability: a randomized controlled trial. Scand J Work Environ Health. 2014 May 1:244-51. [DOI:10.5271/sjweh.3419] [PMID]

32. Gram B, Holtermann A, Bültmann U, Sjøgaard G, Søgaard K. Does an exercise intervention improving aerobic capacity among construction workers also improve musculoskeletal pain, work ability, productivity, perceived physical exertion, and sick leave?: a randomized controlled trial. J. Occup. Environ. Med. 2012 Dec 1;54(12):1520-6. [DOI:10.1097/JOM.0b013e318266484a] [PMID]

33. Karazman R, Kloimüller I, Geissler H, KarazmanMorawetz I. Effects of ergonomic and health training on work interest, work ability and health in elderly public urban transport drivers. Int. J. Ind. Ergon. 2000 May 1;25(5):503-11. [DOI:10.1016/S0169-8141(99)00037-2]

34. Purnawati S, Pangkahila A, Sudewi AA, Sutjana DP. Ergonomics-Job Stress Intervension (Ergo-JSI) reduces stress of employees at National Bank in Denpasar. IJBS. 2012;6(2):59-65 